\title{
Method for Predicting Barge Impact Force Based on Nonlinear Spring Stiffness
}

\author{
Junhu Shao $\mathbb{D}^{1},{ }^{1}$ Yulin Zhan $\left(\mathbb{D},{ }^{2}\right.$ Shuai Song, ${ }^{3}$ Mengqi Cai, ${ }^{1}$ Xiaoping Chen, ${ }^{1}$ and Haiying Y ${ }^{4}$ \\ ${ }^{1}$ School of Architecture and Civil Engineering, Chengdu University, Chengdu, China \\ ${ }^{2}$ Department of Bridge Engineering, Southwest Jiaotong University, Chengdu, China \\ ${ }^{3}$ College of Engineering and Technology, Chengdu University of Technology, Leshan, Sichuan, China \\ ${ }^{4}$ Institute of Technology, Sichuan Normal University, Chengdu, China \\ Correspondence should be addressed to Yulin Zhan; yulinzhan@home.swjtu.edu.cn
}

Received 18 July 2021; Revised 22 November 2021; Accepted 13 December 2021; Published 31 January 2022

Academic Editor: Zeqi Lu

Copyright (C) 2022 Junhu Shao et al. This is an open access article distributed under the Creative Commons Attribution License, which permits unrestricted use, distribution, and reproduction in any medium, provided the original work is properly cited.

\begin{abstract}
Accurate prediction of barge impact force contributes greatly to the research of the soundness of the bridge under barge impact. Toward this end, the calculation method of barge impact force caused by ship-bridge collision is investigated in this study. Firstly, a comparative analysis for different energy conversion relationships is conducted via the high-precision finite element method (HPFEM) and the coupled vessel impact analysis (CVIA). A construction method of nonlinear spring stiffness (NSS) is proposed therefrom. Secondly, a high-precision finite element model is developed to simulate the barge-bridge collision under different barge masses and impact velocities. NSS under each condition is obtained, and the influences of barge mass and impact velocity on NSS are further discussed. An NSS model considering the effects of impact mass and impact velocity is proposed. Lastly, based on the NSS model, a prediction method of barge impact force is introduced. The results show that the impact mass has little influence on the peak value of NSS; however, the impact mass and impact velocity have a great influence on the tail of the NSS curve. According to the characteristics of NSS, four key control points can be extracted and NSS is simplified into a polyline model. The NSS model of the barge is obtained by nonlinear response surface fitting. The impact force can be predicted by combining the simplified NSS model and the proposed method in this study. The proposed method in this paper does not consider the pier stiffness; hence, it can be combined with NSS to quickly estimate the impact force, which can provide a design basis for the impact force in ship-bridge collision design. The rigid wall and a continuous rigid frame bridge impacted by the barge are studied; the results show that the proposed method can reasonably estimate the impact force.
\end{abstract}

\section{Introduction}

With the development of bridge construction and the increase of navigable barges, barge-bridge collision becomes an increasingly prominent problem. The calculation on the barge impact force is one of the key factors for solving this problem. Generally, calculation methods for the barge impact force include equivalent static load method, simplified dynamic load method, and HPFEM. The equivalent static load method is widely applied on account of its simple theoretical framework and convenience $[1,2]$. However, it has an obvious disadvantage as it fails to accommodate and reflect the influence of dynamic effect on the impact force and structural response. As the computer becomes more efficient and gains more progress in accuracy, HPFEM technology was introduced for the calculation of the impact force by barge-bridge collision. HPFEM is a reliable method to calculate the impact force between barge and bridge [3-9] but costs plentiful computer resources and time and requires strong analysis capability. Under this background, a simplified dynamic load method was conceived [10-13].

As a main type of simplified dynamic load method, the CVIA has received extensive attention. In the CVIA model, the ship is simplified as a mass element with a single degree of freedom, where a nonlinear spring is used to link the lumped mass element with a bridge structure. The spring stiffness depends on the relationship between the impact force and the deformation of the bow in the collision 
process. There is no need for tedious contact checks in the calculation, resulting in greatly reducing the calculation time. Compared with the HPFEM and the equivalent static load method, the CVIA attaches importance to both efficiency and accuracy, which has been widely used in recent years. An iterative solution of the CVIA model was later put forward by Consolazio and Cowan, which was verified based on the HPFEM [10, 14, 15]. Yuan et al. [16] introduced the CVIA model for calculating the impact force of whole collision process by considering the multibarge impact pier. The authors verified the reasonableness and efficiency of the CVIA model.

The crucial point of the CVIA model lies in the identification of the NSS as it directly affects the accuracy of calculating the barge impact force; it has been studied by many scholars. In 1983, Meir-Dornberg took the bow of the Europe-IIa ship as the research object, carried out three experimental studies on ship collision, and obtained the relationship between ship bow deformation and impact force [17]. The research findings were later adopted by AASHTO [2]. Fan et al. [18] reported that the NSS under different impact velocities is affected by the strain rate of ship steel materials. The variable factor and average factor were put forward by the authors to enable researchers to refactor the NSS according to different impact velocities. The validity of the NSS model proposed by Fan et al. was proved in the calculation of the dynamic response of ship-bridge collision with the aid of the CVIA model. In order to consider the influence of pier cap heights on the NSS, Fan et al. proposed a method to modify the NSS according to the height of the pier cap [19]. Wang et al. [20] conducted a large number of numerical simulations concerning ship-rigid wall collisions by taking ship bow structure, impact velocity, and ship mass as random variables. 21 random points of time history after nondimensionalizing time histories of impact force were obtained. Based on the random points, a statistical model of NSS was developed and the rationality of the aforesaid model was verified. As ship and barge are different in the bow structure and shape, causing the difference in the NSS, some scholars turned to the study of the NSS of the barge. Based on the HPFEM calculation results of a barge-bridge collision, Consolazio et al. [21] simplified and replaced the curve reflecting the relationship between impact force and bow deformation in the barge-bridge collision with the ideal elastic-plastic model. However, this method did not accurately consider the influence of impact velocity and barge mass on NSS. The NSS is obtained based on the results of HPFEM; then, the dynamic responses of structure can be calculated by CVIA and NSS, but there exists a difference between HPFEM and CVIA, which needs to be discussed. In addition, the impact force calculation methods based on NSS need to be investigated due to the convenience of application. Lastly, the barge NSS is affected by barge mass and impact velocity, and how to obtain the NSS according to barge mass and impact velocity has not been discussed in the existing literature.

In this study, the energy change process of HPFEM and CVIA based on the energy and momentum conservation theorems is deduced and the difference of energy change of the two methods is studied, and further, a method is proposed to establish the NSS model based on time histories of impact force calculated by HPFEM. Afterward, the nonlinear finite element model of barge impact rigid wall is established to study the variation law of NSS under different impact velocities and barge masses. In light of that, a polyline model with five line segments of NSS is proposed, and the CVIA model is simplified as the mass-spring-rigid wall model to predict the impact force with the aid of the NSS model. Furthermore, the accuracy of the proposed barge impact force prediction method is verified by the case of a continuous rigid frame bridge colliding by a barge.

To reasonably predict the NSS, a polyline NSS model with five line segments is proposed. Compared with the NSS obtained by conversion of the bow impact depth and the impact force extracted from the finite element results, the proposed method in this paper has better accuracy. Since the pier stiffness is not considered, the impact force can be estimated quickly by the simplified prediction model, which can provide a design basis for impact force in the ship-collision design.

\section{Research on the Construction Method of NSS}

2.1. Discussion of NSS. The deformation of the bridge at the collision point is much less than that of the barge bow when the barge impacts the bridge. Therefore, the deformation of the bridge is negligible compared to that of the bow. The relationship between impact force and ship bow deformation (i.e., $a-P(a)$ curve) can be regarded as the NSS in the CVIA model [10]. Due to the difficulty and high cost of the bargebridge collision test, most scholars choose to simulate the collision process with the HPFEM to obtain time histories of impact force and bow deformation (see Figure 1), get the NSS, and conduct analysis by employing the CVIA model.

The process of barge-bridge collision can be divided into two stages. The first stage is the cyclic loading and unloading process with the ending sign of the ship speed dropping to $0 \mathrm{~m} / \mathrm{s}$ (the corresponding time is set as $t_{0}$ ). The second stage is the complete unloading stage with the ending sign of the impact force turning to 0 (the corresponding time is set as $T$ ).

Generally, as the stiffness of the collided bridge is much greater than that of the bow, the bow will absorb the majority of the energy; thus, the energy of the structure can be ignored. Considering that the impact force and $a-P(a)$ curve are the discrete data and there is no function expression to demonstrate their relationship, to facilitate the analysis of energy variation law under the CVIA model, the energy and momentum conservation theorems can be expressed by the following equations [18]:

$$
\begin{aligned}
\sum_{i=1}^{n} 0.5 M\left(v_{t_{i}}^{2}-v_{t_{i+1}}^{2}\right) & =\sum_{i=1}^{n}\left[\frac{p\left(a_{t_{i}}\right)+p\left(a_{t_{i+1}}\right)}{2}\right] \cdot\left(a_{t_{i+1}}-a_{t_{i}}\right), \\
\sum_{i=1}^{n} M\left(v_{t_{i}}-v_{t_{i+1}}\right) & =\sum_{i=1}^{n}\left[\frac{p\left(t_{i}\right)+p\left(t_{i+1}\right)}{2}\right] \cdot\left(t_{i+1}-t_{i}\right),
\end{aligned}
$$




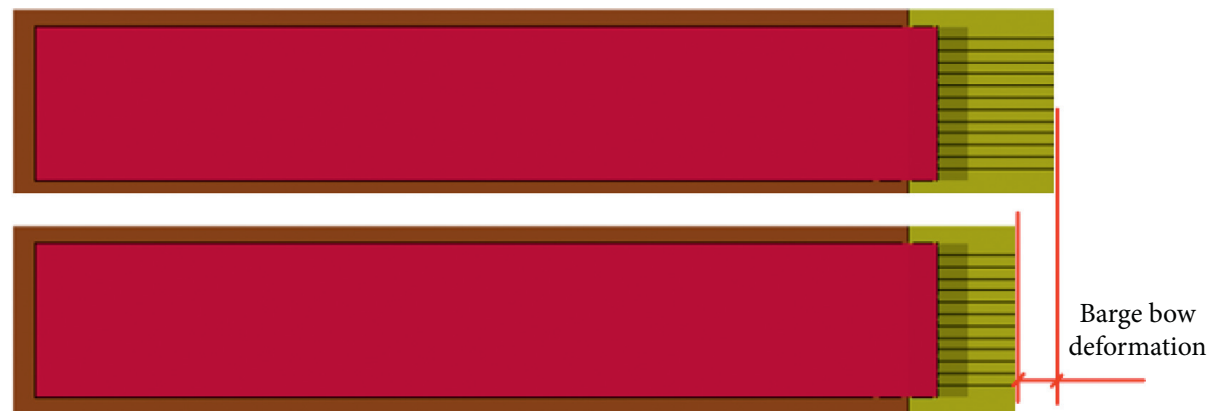

Figure 1: Bow deformation.

where $M$ is the mass of the barge and $n$ is the number of discrete segments of the $a-P(a)$ curve and impact force within the period $0 \sim t_{0}$, in which $n=t_{0} / \Delta t$ and $\Delta t$ is the time step.

According to equation (2), under the same time step, the consistency of impact force under HPFEM and CVIA rests on the consistency of velocities at any time point. Taking equation (1) into the context, it is also clear that there is a one-to-one correspondence between $p\left(a_{t_{i}}\right)$ and $p\left(t_{i}\right)$. In other words, the $a-P(a)$ curve determines to which extent the convergence of results calculated by the two methods can be reached.

Under the HPFEM, given that only the kinetic energy in the direction of impact is taken into account, the systematic energy conservation and momentum theorems can be written as follows [18]:

$$
\begin{aligned}
\sum_{i=1}^{n} 0.5 M\left(v_{t_{i}}^{2}-v_{t_{i+1}}^{2}\right) & =E_{I}+E_{h}+E_{s} \\
\sum_{i=1}^{n} M\left(v_{t_{i}}-v_{t_{i+1}}\right) & =\sum_{i=1}^{n}\left[\frac{p\left(t_{i}\right)+p\left(t_{i+1}\right)}{2}\right] \cdot\left(t_{i+1}-t_{i}\right)
\end{aligned}
$$

where $E_{I}$ represents the internal energy of the system, $E_{h}$ is the hourglass energy of the system, and $E_{s}$ is the sliding energy of the system.

Equations (2) and (4) are consistent in the form; that is, the momentum theorem equations of the two models are the same. For equations (1) and (3), when the energy corresponding to the $a-P(a)$ curve equals the sum of $E_{I}, E_{h}$, and $E_{s}$, the two models also are the same in terms of the energy conservation equation. In this case, the impact force and velocity time histories under the HPFEM and CVIA are consistent.

As aforementioned, the $a-P(a)$ curve is generated based on time histories of impact force and that of bow deformation. For the HPFEM model, the bow deformation time histories curve, which reflects the macroscopical deformation of the bow, can only qualitatively demonstrate the increment of internal energy. Therefore, the estimated sum of $E_{I}, E_{h}$, and $E_{s}$ based on the $a-P(a)$ curve is not necessarily accurate, which also accounts for the difficulty in obtaining accurate barge impact force via NSS directly derived from the bow deformation and impact force under the HPFEM model.
To solve the problem discussed above, the NSS is proposed by combining equations (1) and (2). The NSS curve should meet the following requirements: (a) the energy calculated by the NSS curve shall be equal to the initial kinetic energy of the system; (b) the energy corresponding to the NSS curve during $0 \sim t$ ( $t$ is any time point) shall be equal to the kinetic energy dissipation of the barge.

At the first stage, based on the HPFEM calculation results, the impact force during $0 \sim t_{0}$ can be determined and $t_{0}$ is the time when the velocity nears $0 \mathrm{~m} / \mathrm{s}$. Combined with the speed increment of each period distributed by equation (2), the time histories of bow deformation corresponding to those of impact force can be easily obtained according to equation (1). That is how the NSS is developed at the first loop. In this case, if the proposed NSS curve is inappropriate, the calculated velocity at $t_{0}$ may not be $0 \mathrm{~m} / \mathrm{s}$. If so, the velocity can be set as $v_{b}$.

$v_{b}$ can be allocated to each time period based on distribution coefficient as equation (5) and added to speed increment of each time period at the first loop. According to equation (2), the reconstructed impact force can be altered to make $v_{b}=0$.

$$
c_{t}=\frac{\Delta v_{t}}{\left(v_{0}-v_{b}\right)}
$$

where $\Delta v_{t}$ is the velocity variation at each period when the NSS is determined at the first loop.

Based on equation (5), $v_{i}^{\prime}$, the distributed velocity at the different moment, can be obtained from $v_{b}$, according to which and combined with equation (2), a time history of impact force relating to $p^{\prime}\left(t_{i}, v_{b}\right)$ can thus be developed as follows:

$$
\sum_{i=1}^{n}\left[\frac{p^{\prime}\left(t_{i}, v_{b}\right)+p^{\prime}\left(t_{i+1}, v_{b}\right)}{2}\right] \cdot\left(t_{i+1}-t_{i}\right)=\sum_{i=1}^{n} M\left(v_{t_{i}}^{\prime}-v_{t_{i+1}}^{\prime}\right),
$$

where $p^{\prime}\left(t_{i}, v_{b}\right)$ represents the virtual time histories of impact force and is a function of timing and $v_{b}$ and $v_{i}^{\prime}$ is calculated according to $c_{t}$.

For any period during impact, the following equations can be established: 


$$
\begin{aligned}
& M\left(v_{t_{i}}-v_{t_{i+1}}\right)=\left[\frac{p\left(t_{i}\right)+p\left(t_{i+1}\right)}{2}\right] \cdot\left(t_{i+1}-t_{i}\right), \\
& M\left(v_{t_{i}}^{\prime}-v_{t_{i+1}}^{\prime}\right)=\left[\frac{p^{\prime}\left(t_{i}, v_{b}\right)+p^{\prime}\left(t_{i+1}, v_{b}\right)}{2}\right] \cdot\left(t_{i+1}-t_{i}\right) .
\end{aligned}
$$

The following equation can be obtained via dividing equation (8) by (7):

$$
\frac{\left(v_{t_{i}}^{\prime}-v_{t_{i+1}}^{\prime}\right)}{\left(v_{t_{i}}-v_{t_{i+1}}\right)}=\frac{p^{\prime}\left(t_{i}, v_{b}\right)+p^{\prime}\left(t_{i+1}, v_{b}\right)}{p\left(t_{i}\right)+p\left(t_{i+1}\right)} \text {. }
$$

Suppose that $\Delta v_{t}=v_{t_{i}}-v_{t_{i+1}}$, by substituting equation (5) into (9), the following equation can be obtained:

$$
v_{t_{i}}^{\prime}-v_{t_{i+1}}^{\prime}=\frac{v_{b} \cdot \Delta v_{t}}{\left(v_{0}-v_{b}\right)} \text {. }
$$

Then, substituting equation (10) into (9) yields the relationship between the constructed impact force and the actual one (HPFEM):

$$
\frac{p^{\prime}\left(t_{i}, v_{b}\right)+p^{\prime}\left(t_{i+1}, v_{b}\right)}{p\left(t_{i}\right)+p\left(t_{i+1}\right)}=\frac{v_{b}}{v_{0}-v_{b}} .
$$

According to equation (11), the correction coefficient of impact force can be defined as follows:

$$
\alpha=\frac{p\left(t_{i}\right)+p\left(t_{i+1}\right)}{p\left(t_{i}\right)+p\left(t_{i+1}\right)+p^{\prime}\left(t_{i}, v_{b}\right)+p^{\prime}\left(t_{i+1}, v_{b}\right)}=\frac{v_{0}-v_{b}}{v_{0}} .
$$

2.2. Construction Method of NSS. According to the induction and analysis mentioned above, the steps for the determination of NSS are as follows:

(a) Establish a barge-rigid-wall collision model under HPFEM.

(b) Obtain the barge-bridge impact force from HPFEM and divide the impact duration from the beginning to the uploading into $n$ segments according to the time step.

(c) According to the impact force and equation (2), calculate the impulse increment from $t_{i}$ to $t_{i+1}$, as well as corresponding velocity increment $\Delta v_{i}$ at the same period:

$$
\Delta v_{i}=\frac{\left[p\left(t_{i}\right)+p\left(t_{i+1}\right) / 2\right] \cdot\left(t_{i+1}-t_{i}\right)}{M}, \quad i=1,2, \cdots n .
$$

The velocity at any time can be calculated using the following equation:

$$
v_{j}=v_{0}-\sum_{i=1}^{j} \Delta v_{i}, \quad j=1,2, \cdots n .
$$

(d) According to the momentum variation corresponding to various times, the bow deformation increment during $t_{i} \sim t_{i+1}$ can be obtained:

$$
\Delta a_{i}=\frac{M\left(v_{t_{i}}^{2}-v_{t_{i+1}}^{2}\right)}{p\left(t_{i}\right)+p\left(t_{i+1}\right)}, \quad i=1,2, \ldots n .
$$

(e) Accumulate the bow deformation increment calculated in step $(\mathrm{d})$ :

$$
a_{j}=\sum_{i=1}^{j} \Delta a_{i}, \quad j=1,2, \ldots n .
$$

(f) Suppose that the barge velocity at $t_{0}$ is $v_{b}^{\prime}$, examine whether $\left|v_{b}^{\prime}-\varepsilon\right|=0$, where $\varepsilon$ is a relatively smaller value; calculate the correction coefficient of impact force $\alpha$ at the first loop of NSS determination, which is unnecessary in a subsequent iteration. If the equation is false, turn to step (7), or the calculation is closed since the NSS curve can be directly obtained based on the calculated bow deformation and barge impact force.

(g) Calculate distribution coefficient of the velocity at $t_{i}$ :

$$
c_{i}=\frac{\Delta v_{i}}{\left(v_{0}-v_{b}\right)}, \quad i=1,2, \ldots n .
$$

According to equation (18), calculate the velocity increment at $t_{i}$ distributed from the residual velocity $v_{b}$.

$$
\Delta v_{i}^{\prime}=\frac{v_{b} \times \Delta v_{i}}{\left(v_{0}-v_{b}\right)}, \quad i=1,2, \ldots n
$$

And calculate the distributed load $P_{i+1}^{\prime}$ :

$$
p_{i+1}^{\prime}=2 M \cdot \Delta v_{i} \cdot\left(t_{i+1}-t_{i}\right)-p_{i}^{\prime}, \quad i=1,2, \ldots n .
$$

Then, the barge impact force can be updated as follows:

$$
P_{i, k+1}=P_{i, k}+P_{i, k}^{\prime}
$$

where $P_{i, k}$ is the impact force at $t_{i}$ after the $k$ th iteration and $k=1,2, \ldots n$, and $P_{i, k}^{\prime}$ is the virtual impact force at $t_{i}$ after $k$ th iteration.

(f) Turn to step (3) and continue to calculate.

The flow chart of NSS construction is shown in Figure 2.

\section{NSS Parameter and Model Research for Barge Collision}

The main position subjected to barge impact is the bridge substructure. The dimension and shape of the substructure have a significant influence on the NSS [22]. Yuan and Harik [23] studied the influence of $b_{c} / B$ (ratio of pier width to barge width) and $D / B$ (ratio of pier diameter to barge width) on the $a-P(a)$ curve. The results show that the $a-P(a)$ curve increases as $b_{c} / B$ and $D / B$ increase. Since the larger $a-P(a)$ 


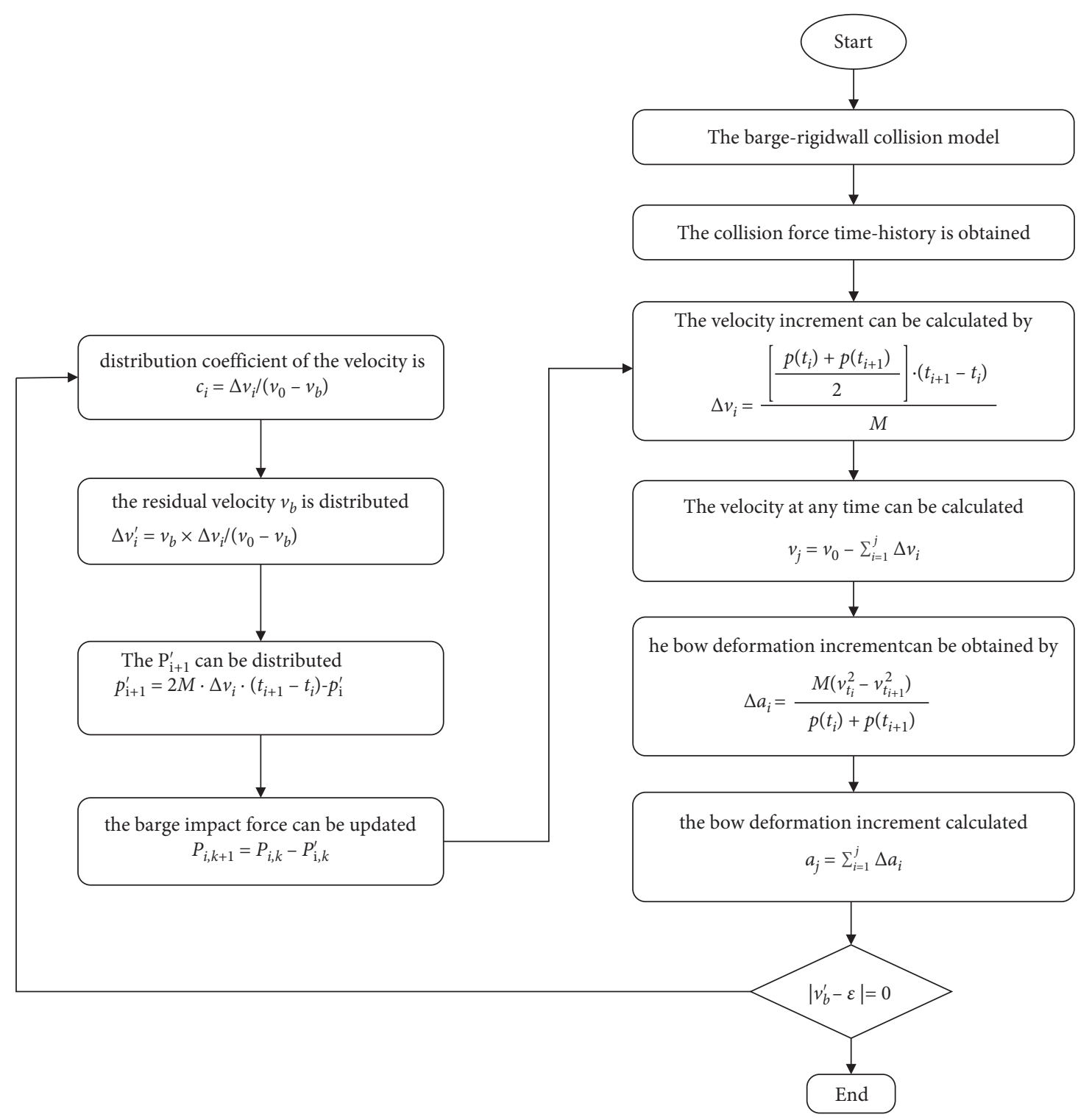

FIgURE 2: The flow chart of NSS construction.

curve may yield a larger impact force estimate, in compliance with the most unfavorable principle, the actual pier is assumed to be modeled using a rigid wall with enough width to carry out the NSS parameter study.

The finite element model of barge-rigid-wall collision is shown in Figure 3, where the barge body is modeled using shell elements with the element size ranging from $0.1 \mathrm{~m}$ to $0.2 \mathrm{~m}$, and the cargo is modeled using solid elements without considering the cargo contributes to barge bow stiffness.

The bow part and its stiffeners are modeled using an elastic-plastic kinematic hardening model (* MAT_PLASTIC_KINEMATIC). Since the hull and cargo are not directly involved during the collision and their nonlinear degrees are relatively low, they are modeled using elastic material $\left(^{*}\right.$ *MAT_ELASTIC). The density of the cargo is determined by barge masses as the case may be. All material parameters are shown in Table 1.
3.1. Effects of Barge Mass. There are three barge masses of $800 \mathrm{t}, 1000 \mathrm{t}$, and $1200 \mathrm{t}$ adopted in this section, and the impact speed is $3 \mathrm{~m} / \mathrm{s}$. The calculated impact force, bow deformation, NSS, and correction coefficient of impact force are shown in Figure 4.

Figure 4(a) shows the time histories of impact force under different barge masses. It can be seen from the figure that the peak impact force is little influenced by the barge mass, while the characteristics among the three impact force curves are quite different, mainly represented as the increasing impact duration as barge mass rises.

Figure 4(b) presents the time histories of the bow deformation. The bow deformation increases with the increase of barge mass. The main reason is that as the barge mass increases, the initial kinetic energy of the barge increases correspondingly, which requires larger bow deformation to absorb the increased kinetic energy. 


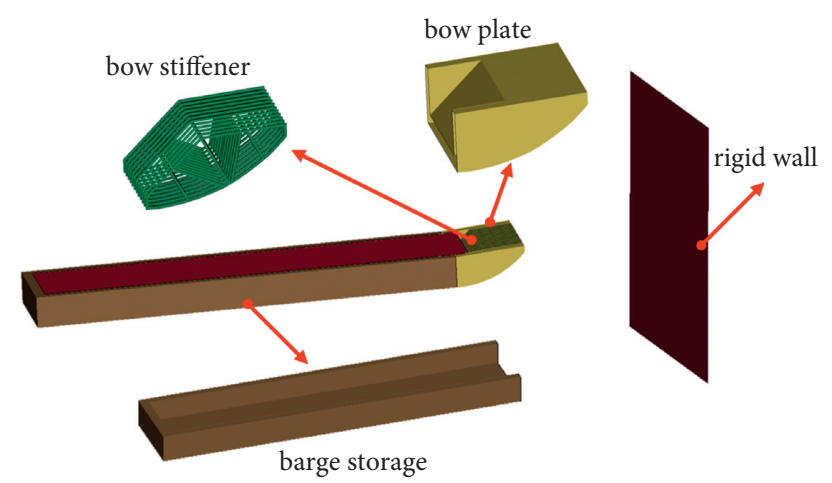

Figure 3: Finite element model of the barge-rigid wall collision.

TABLE 1: Material parameters of barge.

\begin{tabular}{lcccccc}
\hline Type & Density $\left(\mathrm{kg} / \mathrm{m}^{3}\right)$ & Elastic modulus $(\mathrm{MPa})$ & Poisson & Yield strength $(\mathrm{MPa})$ & Tangent modulus $(\mathrm{GPa})$ & Failure strain \\
\hline Bow & 7800 & $2.1 \times 10^{5}$ & 0.3 & 235 & 1.18 & - \\
Hull & 7800 & $2.1 \times 10^{5}$ & 0.3 & - & - \\
Cargo & Variable & $2.1 \times 10^{2}$ & 0.3 & & - \\
\hline
\end{tabular}

The NSS under different barge masses are computed and obtained by the aforementioned NSS construction method. The results are shown in Figure 4(c).

According to the characteristics of the results shown in Figure 4(c), the NSS curve can be divided into three stages: Stage I (initial elastic loading stage); Stage II (plastic loading stage); and Stage III (elastic unloading stage). At the initial elastic loading stage, the $a-P(a)$ curve is almost linear. At this stage, as the barge bow just collides with the structure, components of the bow are temporarily in the elastic state. This stage does not last too long. It generally sustains about $0.02 \mathrm{~s}$ and causes bow deformation to be $0.086 \mathrm{~m}$.

The next stage is the plastic loading stage, which lasts for a long time and involves a relatively complex collision process. As revealed by Figure 4(c), this stage is characterized by four end-to-end descending line segments. This is because some bow components reach ultimate yield strength and remove from the barge structure in this stage. As the deformation of the bow increases, the impact force tends to correspondingly decrease; this stage is plastic unloading.

The third stage is the elastic unloading stage, which lasts only for a short duration. After the elastic unloading, only fractions of the bow deformation can be recovered. It can be considered that the barge kinetic energy is completely converted into deformation energy. As shown in Figure 4(d), the correction coefficient of impact force obtained in the first iteration is between 1.0 and 1.05, indicating a satisfactorily accurate NSS obtained in the first iteration.

3.2. Effects of Impact Velocity. A simulation of collision between a barge and rigid wall was carried out with barge mass set at $1000 \mathrm{t}$ and impact velocities at $2 \mathrm{~m} / \mathrm{s}, 2.5 \mathrm{~m} / \mathrm{s}, 3 \mathrm{~m} /$ $\mathrm{s}, 3.5 \mathrm{~m} / \mathrm{s}, 4 \mathrm{~m} / \mathrm{s}$, and $4.5 \mathrm{~m} / \mathrm{s}$, respectively. The simulation results are shown in Figure 5.

As shown in Figure 5(a), the impact force duration and the bow deformation increase with the increased impact velocity. As shown in Figure 5(b), the bow deformation of the barge bow increases as the initial momentum of the barge increases. As shown in Figure 5(c), the changes of nonlinear spring stiffness can be divided into 3 stages in which the second one can be similarly viewed to be characterized by four end-to-end descending line segments.

When impact velocity ranges from $4 \mathrm{~m} / \mathrm{s}$ to $4.5 \mathrm{~m} / \mathrm{s}$, fluctuations occur on the NSS curve. As shown in Figure 5(d), the correction coefficient of impact force in the first iteration ranges from 1.0 to 1.05 , the accuracy of nonlinear spring stiffness obtained in the first iteration is acceptable.

3.3. Nonlinear Spring Stiffness of Barge-Rigid Wall Collision. According to the parametric study on NSS, NSS can be modeled in a simplified manner as shown in Figure 6. Based on the previous analysis, four key points on the NSS model are related to the barge mass and impact velocity.

Fan et al. [24] considered that the maximum crush depth is related to the elastic-plastic internal energy of the barge. Bow deformation can be viewed as a macroscopic reflection of the increased internal energy. Most of the initial kinetic energy is converted into the elastic-plastic internal energy of the barge. Thus, it is considered that bow deformation is closely related to the barge initial kinetic energy. Relations between bow deformation and barge initial kinetic energy at 4 key points are shown in Table 2 .

Figure 7 shows the statistical relations between the bow deformation and initial kinetic energy of sample points in Table 2. In charts of Figure 6 are quadratic polynomial fitting equations for the bow deformation and initial kinetic energy of sample points.

The impact force is related to the barge mass and the impact velocity [2]. Table 3 presents the impact forces under conditions of different impact velocities and barge 


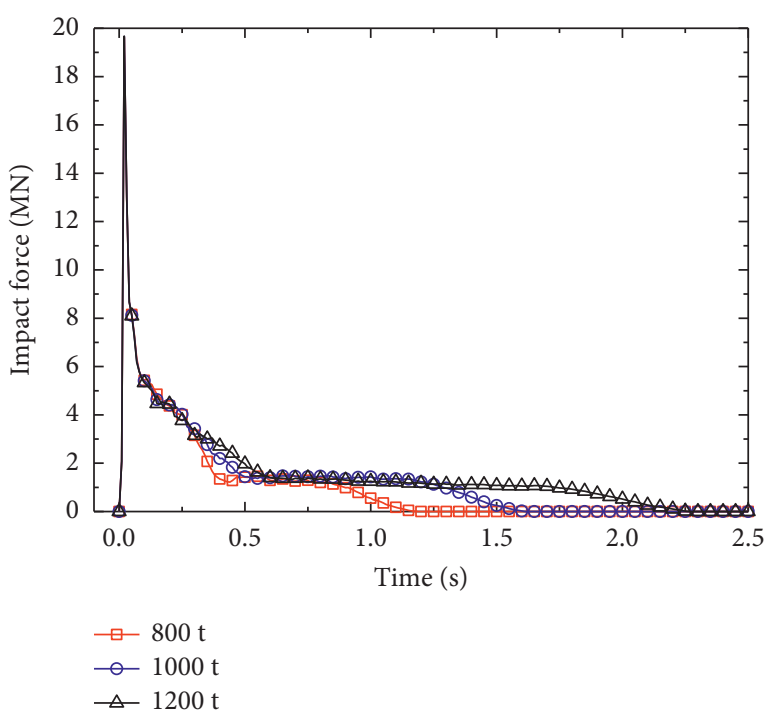

(a)

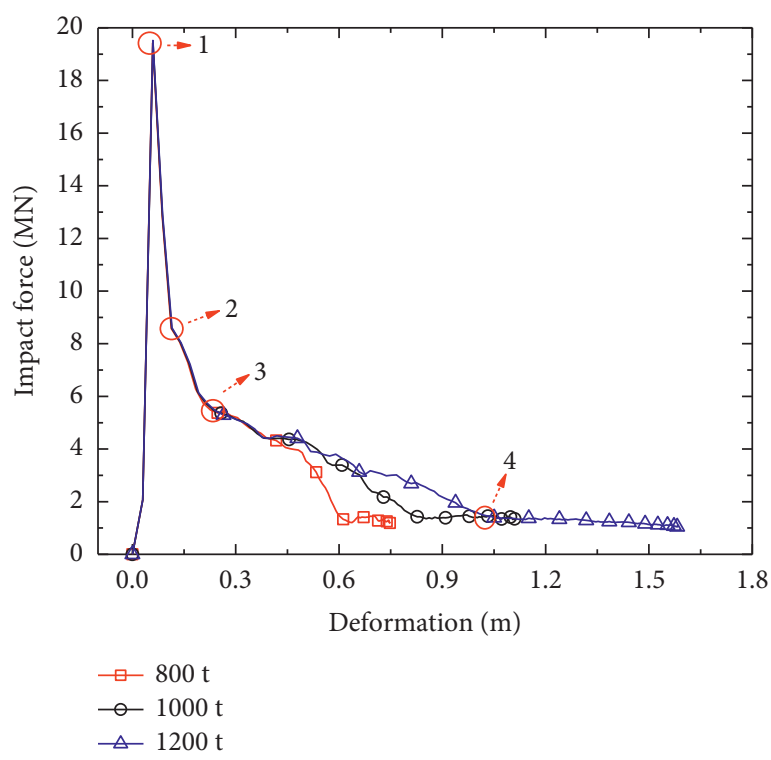

(c)

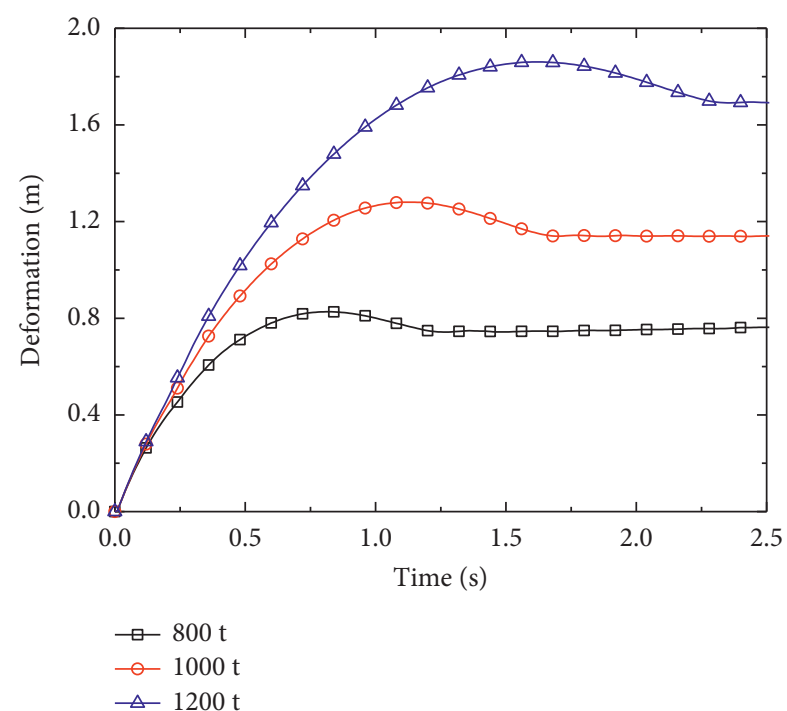

(b)

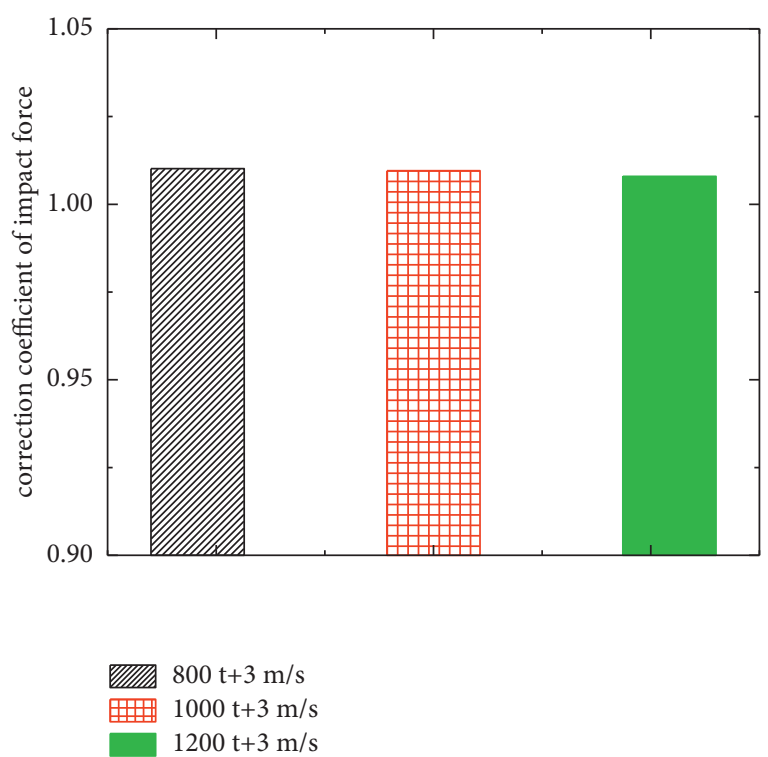

(d)

FIGURE 4: Simulation results under varying barge impact on the rigid wall. (a) Impact force under varying barge mass. (b) Bow deformation under varying barge mass. (c) NSS incurred under varying barge mass. (d) Correction coefficient of impact force.

mass. To predict the impact force by impact velocity and barge mass, a response surface methodology (RSM) is used. RSM was proposed by the mathematicians Box and Wilson in 1951, which was first used for chemical analysis. In 1990, Bucher and Bourgund put forward a response surface function without cross terms [25], which is expressed as follows:

$$
G(X)=a+\sum_{i=1}^{n} b_{i} x_{i}+\sum_{i=1}^{n} c_{i} x_{i}^{2}
$$

In this equation, $a, b_{i}$, and $c_{i}$ are the coefficients of RSF, which are determined by $2 N+1$ sample points. Those sample points are selected in the following:

$$
\begin{aligned}
& \left(x_{1}^{k}, x_{2}^{k}, \ldots x_{n}^{k}\right), \\
& \left(x_{1}^{k}, \ldots, x_{i \text { max }}^{k}, \ldots, x_{n}^{k}\right), \quad i=1,2, \ldots, n, \\
& \left(x_{1}^{k}, \ldots, x_{i \text { min }}^{k}, \ldots, x_{n}^{k}\right), \quad i=1,2, \ldots, n .
\end{aligned}
$$

Table 4 shows the coefficient of RSF obtained by fitting the sample points with RSF. With the impact velocity and barge mass, the coefficient of RSF can be used to calculate the impact force of each key point.

As the unloading stiffness of NSS cannot be calculated by use of the proposed method, hence the unloading stiffness can be obtained from HPFEM. Firstly, the impact force and bow deformation are got by HPFEM, then the unloading stiffness can be calculated by equation (23) and their results 


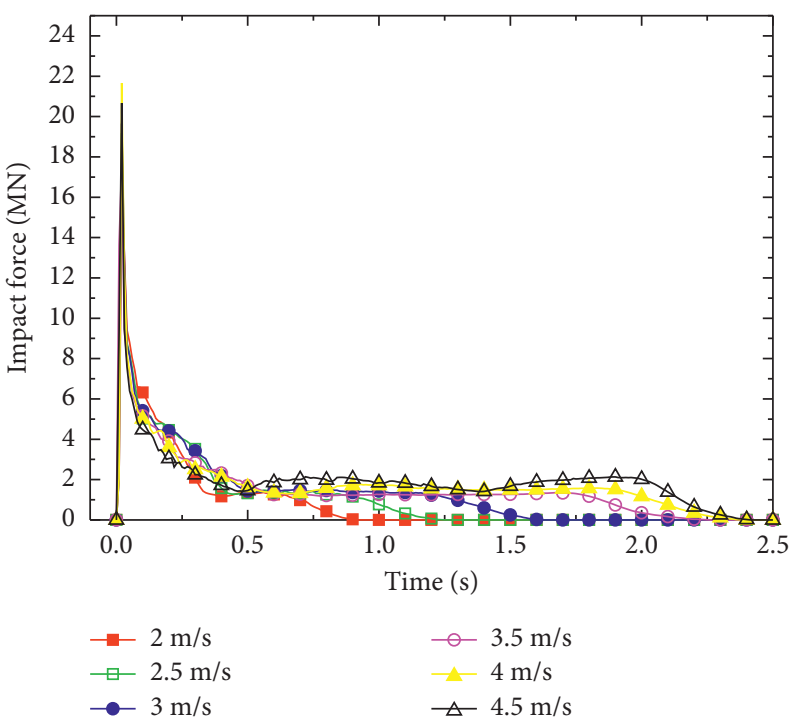

(a)

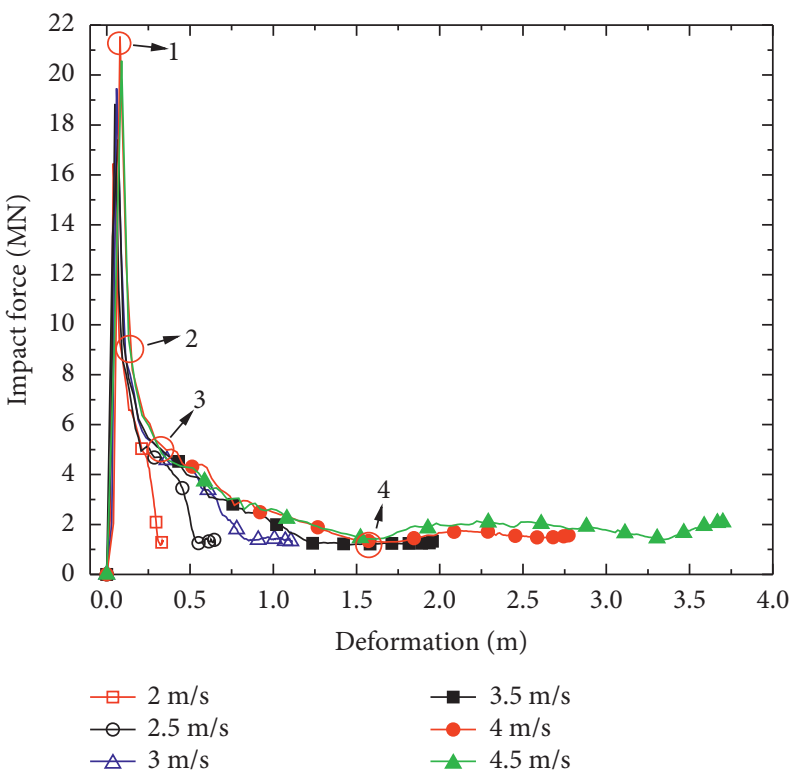

(c)
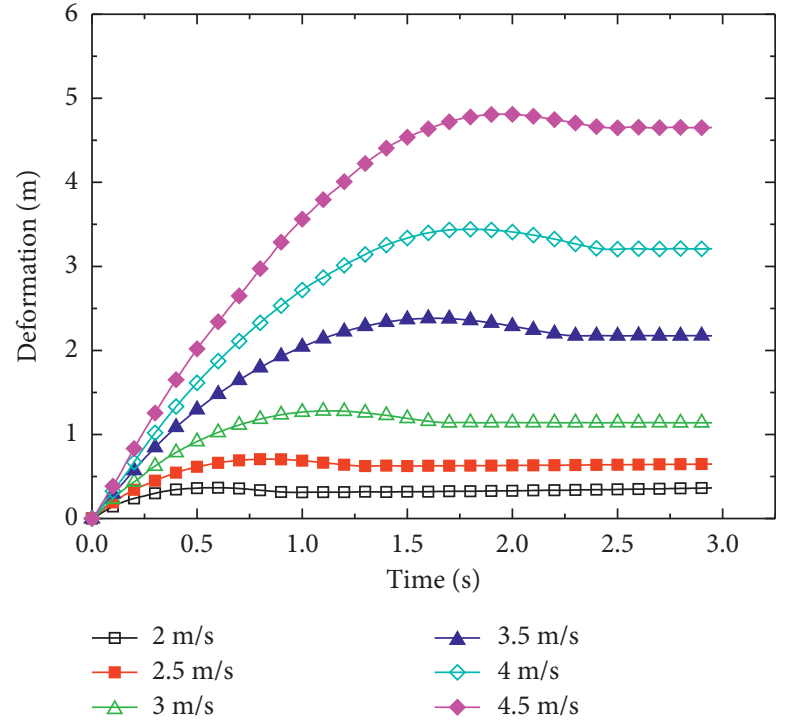

(b)

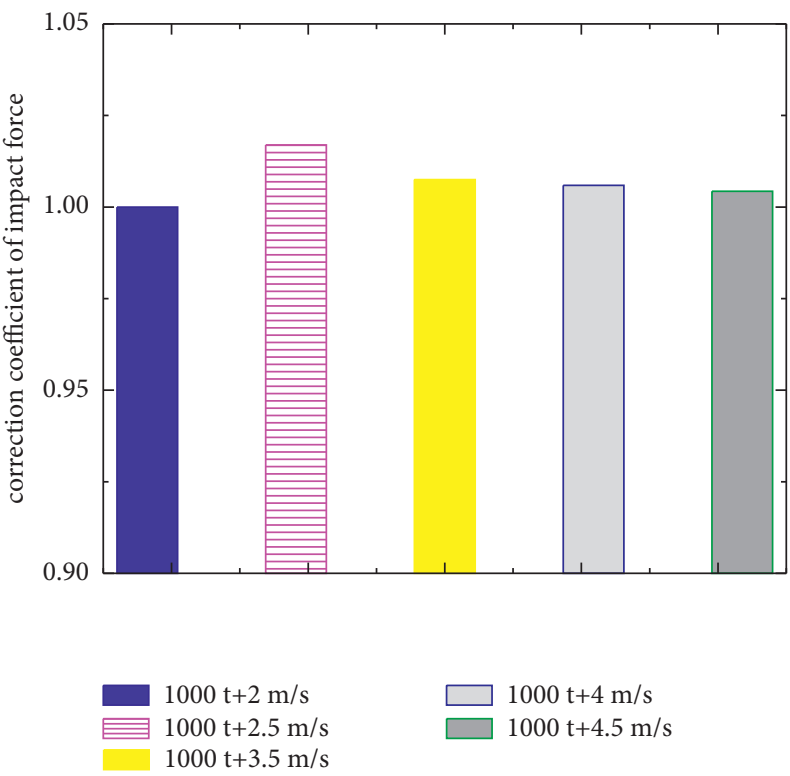

(d)

FIGURE 5: Simulation results vary with the impact velocity of barge impact on rigid wall. (a) Impact force varies with impact velocity. (b) Bow deformation varies with impact velocity. (c) NSS varies with impact velocity. (d) Correction coefficient of impact force.

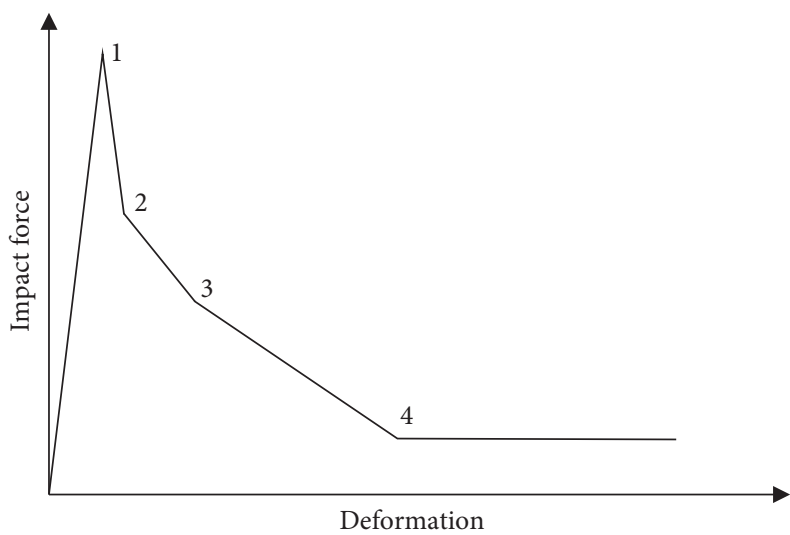

FIGURE 6: Simplified NSS. 
TABLE 2: Sample points of Initial kinetic energy and bow deformation.

\begin{tabular}{lcccc}
\hline IKE $(\mathrm{kJ})$ & BD (point 1) $(\mathrm{m})$ & BD (point 2) $(\mathrm{m})$ & BD (point 3) $(\mathrm{m})$ & BD $($ point 4$)(\mathrm{m})$ \\
\hline 2000 & 0.039 & 0.075 & 0.133 & 0.318 \\
2250 & 0.059 & 0.108 & 0.185 & 0.353 \\
3125 & 0.049 & 0.093 & 0.207 & 0.535 \\
3600 & 0.059 & 0.113 & 0.247 & 0.212 \\
3920 & 0.054 & 0.079 & 0.212 & 0.702 \\
4500 & 0.059 & 0.114 & 0.370 & 0.844 \\
4950 & 0.059 & 0.115 & 0.217 & 0.966 \\
5400 & 0.059 & 0.115 & 0.245 & 1.061 \\
5512.5 & 0.068 & 0.100 & 0.248 & 1.073 \\
6125 & 0.068 & 0.100 & 0.325 & 1.223 \\
8000 & 0.079 & 0.154 & 0.551 & 1.514 \\
10125 & 0.089 & 0.131 & & 3.340 \\
\hline
\end{tabular}

IKE: initial kinetic energy; BD: bow deformation.

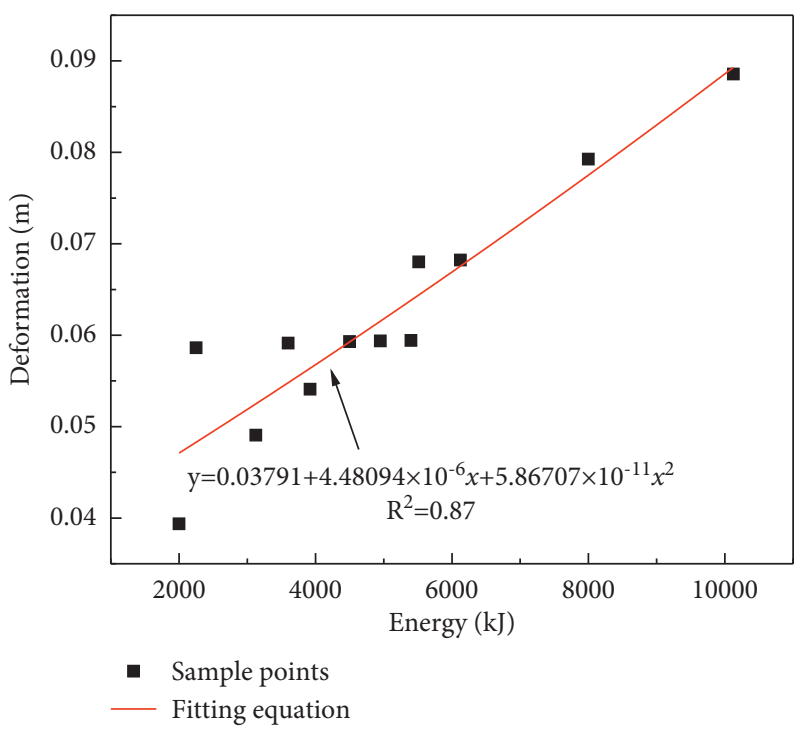

(a)

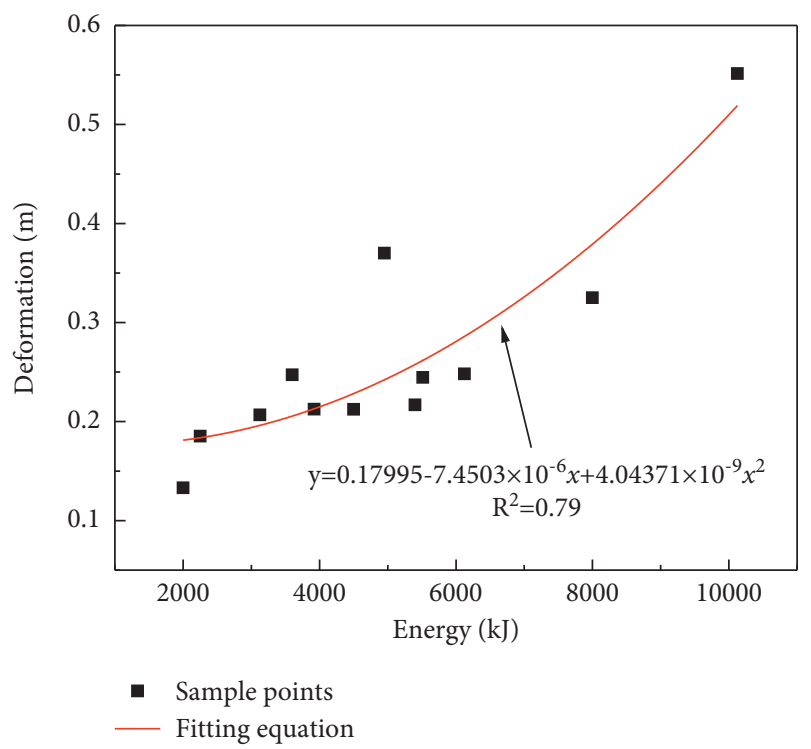

(c)

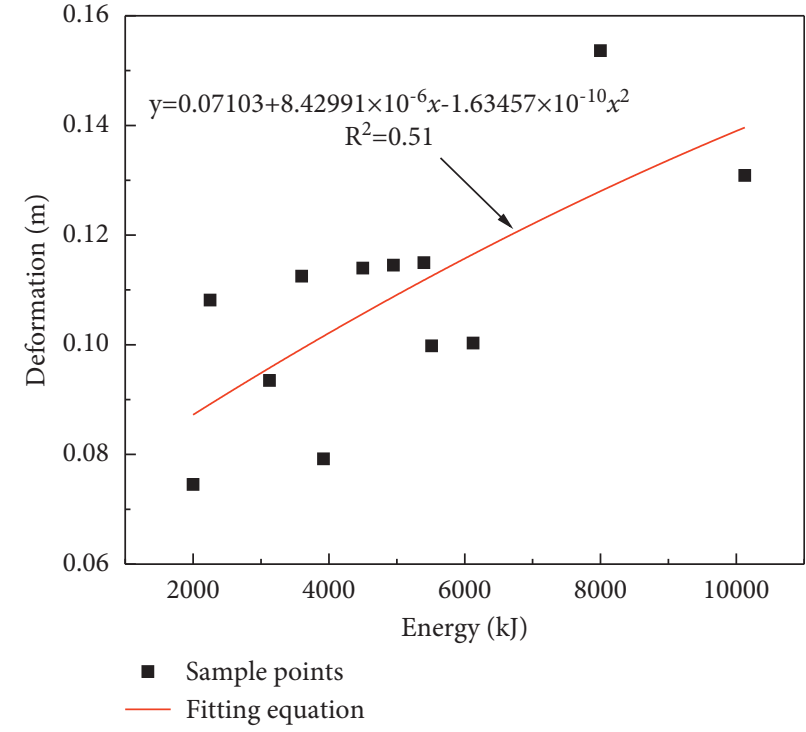

(b)

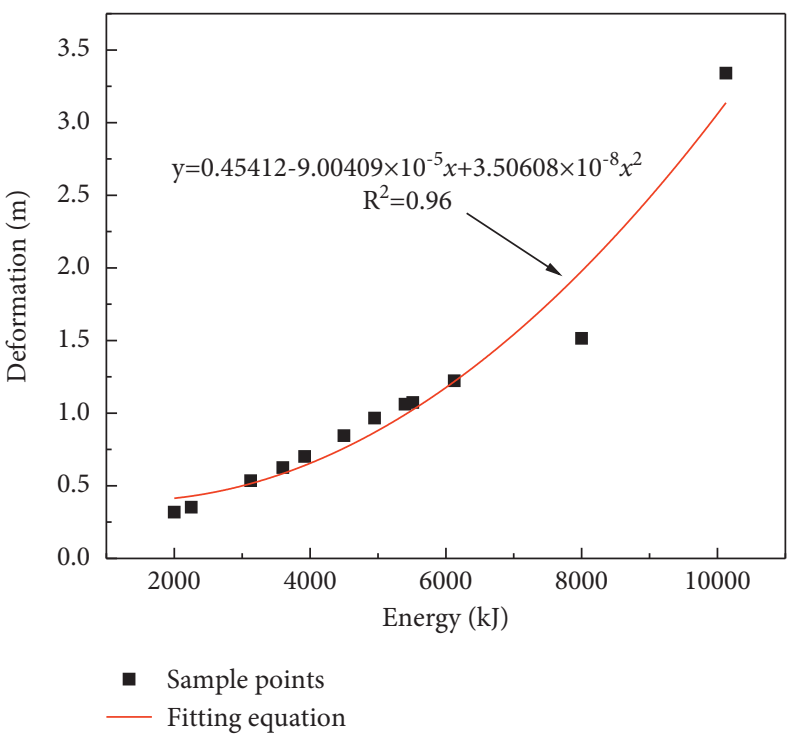

(d)

Figure 7: Fitting curve of bow deformation. (a) Fitting curve of sample point 1. (b) Fitting curve of sample point 2. (c) Fitting curve of sample point 3. (d) Fitting curve of sample point 4. 
TABLe 3: The sample points for fitting.

\begin{tabular}{|c|c|c|c|c|c|}
\hline \multicolumn{6}{|l|}{ Case } \\
\hline \multicolumn{6}{|l|}{$\begin{array}{l}\text { Case } \\
\text { Key point }\end{array}$} \\
\hline 1 & 19.20 & 19.47 & 19.52 & 16.46 & 20.58 \\
\hline 2 & 8.52 & 8.59 & 8.60 & 9.42 & 9.44 \\
\hline 3 & 5.72 & 5.75 & 5.74 & 6.58 & 4.06 \\
\hline 4 & 1.14 & 1.39 & 1.37 & 1.23 & 1.40 \\
\hline
\end{tabular}

C-P1-P2: P1 is barge mass; P2 is impact speed. For example, C-500-3 is the case of barge impact rigid wall with barge mass $500 \mathrm{t}$ and impact speed $3 \mathrm{~m} / \mathrm{s}$.

TABLE 4: Coefficient of response surface function.

\begin{tabular}{lccccc}
\hline Coefficient of RSF & & & & \\
Key point & $a$ & $b 1$ & $b 2$ & $c 1$ & $c 2$ \\
\hline 1 & 4.294 & $1.112 \times 10^{-3}$ & 7.531 & $-3.854 \times 10^{-7}$ & $-9.054 \times 10^{-1}$ \\
2 & 14.275 & $2.692 \times 10^{-4}$ & -3.635 & $-9.200 \times 10^{-8}$ & $5.602 \times 10^{-1}$ \\
3 & 7.418 & $2.979 \times 10^{-4}$ & $-2.566 \times 10^{-1}$ & $-1.590 \times 10^{-7}$ & $-1.156 \times 10^{-1}$ \\
4 & $-4.021 \times 10^{-1}$ & $1.827 \times 10^{-3}$ & $4.671 \times 10^{-1}$ & $-8.845 \times 10^{-7}$ & $-6.117 \times 10^{-2}$ \\
\hline
\end{tabular}

are presented in Table 5. The unloading stiffness adopted in this paper is $1.41 \times 10^{7} \mathrm{~N} / \mathrm{m}$, which is the average of the unloading stiffness of the five cases.

$$
E_{u}=\frac{F_{0}}{\left(D_{T}-D_{0}\right)} .
$$

In equation (23), $F_{0}$ is the impact force when the barge velocity is $0 \mathrm{~m} / \mathrm{s}$ and $D_{T}$ is the bow deformation when the impact force is $0 . D_{0}$ is the bow deformation when barge velocity is $0 \mathrm{~m} / \mathrm{s}$.

\section{Simplified Prediction Method of Barge Impact Force}

The CVIA model refers to a simplified model for the bargebridge collision system as shown in Figure $8[10,18]$. In this model, the barge is simplified as a lumped mass and the bridge structure is discretized by the finite element method, and a nonlinear spring is set to connect the lumped mass and impact point of the discretized bridge structure. In this model, the lumped mass represents the barge mass that includes hydrodynamic added mass, and the NSS is the simplified $a-P(a)$ curve generally.

The barge dynamic equation and the bridge dynamic equation are established separately and then integrated by the impact force. Through the iterative solution, related results, such as impact force, bridge structure displacement, barge velocity, acceleration, and so on, can be obtained. In this process of calculation, the NSS directly affects the accuracy of the solution; thus, the determination of the NSS is a significant part of CVIA.

As the stiffness of the barge bow is generally far less than that of the bridge substructure, the bridge substructure is usually regarded as a rigid wall in the study of the $a-P(a)$ curve. Under the above conditions, the dynamic responses of the bridge that are calculated by the predicted impact force are a conservative result [20]. According to the most unfavorable principle of engineering, this study simplified bridge structure to the rigid wall of the CVIA model and proposed a simplified Coupled Vessel Impact Analysis (SCVIA) model for impact force prediction. The schematic diagram is shown in Figure 9.

Because the impact force equals the reaction force of the rigid wall, and the rigid wall is represented by the impact force, the model in Figure 9 can be simplified to the model in Figure 10. Based on D'Alembert's principle, the barge motion equation can be expressed as follows:

$$
M_{s} \ddot{u}_{s}-K_{s}\left(u_{s}\right) u_{s}=P(t),
$$

where $M_{s}$ represents the barge mass, $K_{s}\left(u_{s}\right)$ represents the NSS, $\ddot{u}_{s}$ represents the barge acceleration, $u_{s}$ represents the bow deformation, and $P(t)$ represents the impact force.

Equation (24) can be solved by numerical analysis in which the central difference method is adopted [11]. As the convergence of the central difference method depends on the number of time steps, a time step of $0.01 \mathrm{~s}$ is suggested by Cowan to be the minimum time step of the central difference method in solving the very equation.

In this study, the Newmark- $\beta$ method is used to solve the equation of barge motion. When the integral constant is reasonably set, the method will unconditionally converge to the correct solution. Therefore, the Newmark- $\beta$ method is more suitable for solving the dynamic equation.

Two basic equations of the Newmark- $\beta$ method are shown as follows [26]:

$$
\begin{aligned}
& \dot{u}_{i+1}=\dot{u}_{i}+(1-\gamma) \Delta t \ddot{u}_{i}+\gamma \Delta t \ddot{u}_{i+1}, \\
& u_{i+1}=u_{i}+\Delta t \dot{u}_{i}+\left(\frac{1}{2}-\beta\right) \Delta t^{2} \ddot{u}_{i}+\beta \Delta t^{2} \ddot{u}_{i+1},
\end{aligned}
$$

where $\Delta t=$ the number of integral time steps; $\ddot{u}_{i+1}=$ barge acceleration, $\dot{u}_{i+1}=$ barge velocity, and $u_{i+1}=$ barge displacement at the time of $i+1 ; \quad \ddot{u}_{i}=$ barge acceleration, $\dot{u}_{i}=$ barge velocity, and $u_{i}=$ barge displacement at the time of $i$; and $\gamma$ and $\beta$ are the integral constants which are, respectively, set at 0.5 and 0.25 for the unconditional convergence. 
TABLE 5: Unloading stiffness.

\begin{tabular}{lccccc}
\hline Tonnage $(\mathrm{t})$ & Velocity $(\mathrm{m} / \mathrm{s})$ & Unloading stiffness $(\mathrm{N} / \mathrm{m})$ & Tonnage $(\mathrm{t})$ & Velocity $(\mathrm{m} / \mathrm{s})$ & Unloading stiffness $(\mathrm{N} / \mathrm{m})$ \\
\hline 1000 & 2 & $2.57 \times 10^{7}$ & 500 & 3 & $1.43 \times 10^{7}$ \\
1000 & 3 & $1.04 \times 10^{7}$ & 1200 & 3 & $6.57 \times 10^{6}$ \\
1000 & 4.5 & $1.36 \times 10^{7}$ & Average of unloading stiffness & $1.41 \times 10^{7}$ \\
\hline
\end{tabular}

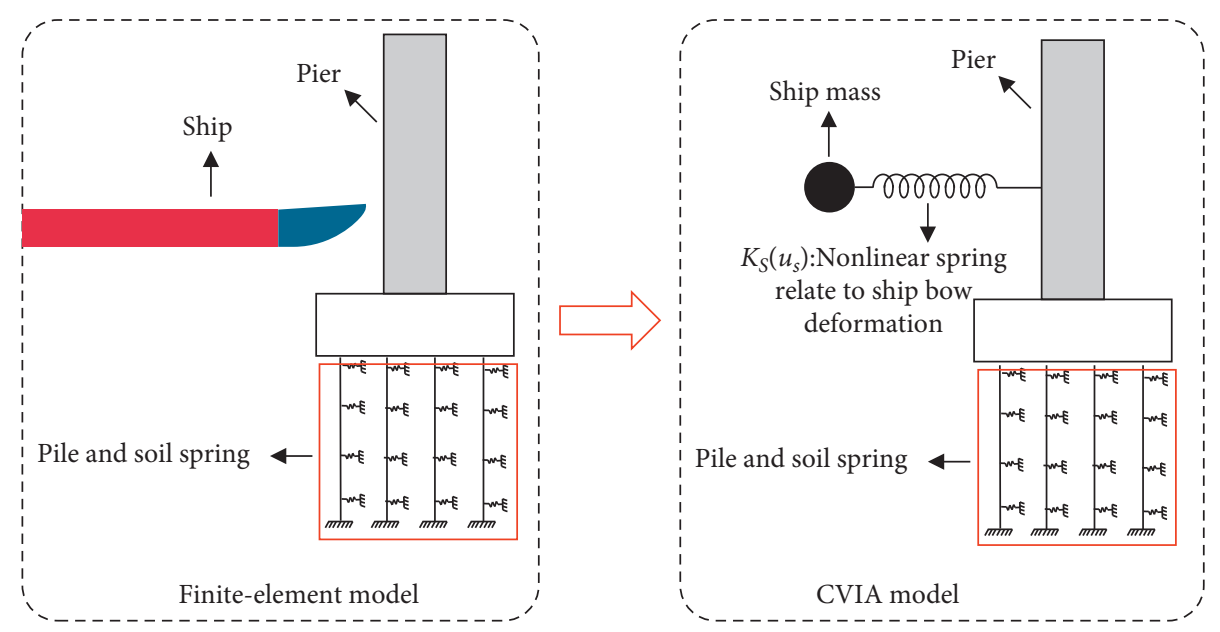

Figure 8: CVIA simplified model [10, 18].

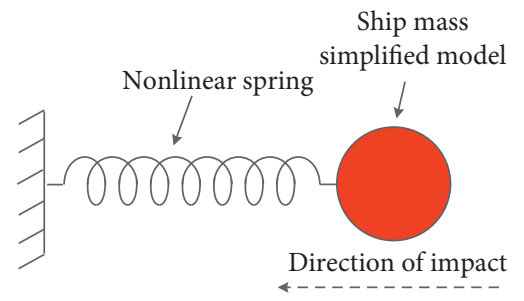

FIgURE 9: Simplified model of the barge impact rigid wall model.

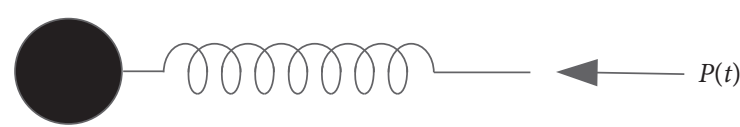

FIgURE 10: Model of barge momentum.

The barge acceleration at the time of $t_{i+1}$ is calculated by equation (24):

$$
\ddot{u}_{s}^{i+1}=\frac{P^{i+1}+K_{s}\left(u_{s}^{i+1}\right) u_{s}^{i+1}}{M_{s}} .
$$

Substituting equation (27) into (25) and (26), the barge velocity and displacement at the time of $t_{i+1}$ can be calculated by the barge acceleration, velocity, and displacement at the time of $t_{i}$.

Actually, the impact force is unpredictable and needs to be acquired via the iterative method. The iterative process is shown as follows [11]:

(1) Under the specified initial conditions, the barge displacement is expressed by $u_{s}^{0}$; barge velocity, $\dot{u}_{s}^{0}$; barge acceleration, $\ddot{u}_{s}^{0}$; and impact force, $p_{c(0)}^{i}$.
(2) Suppose that the impact force at the time of $t_{i+1}$ generated in the $k$ th iteration is $p_{c(k)}^{i+1}$, when $k=1$, $p_{c(k)}^{i+1}=p_{c}^{i}$; when $k \neq 1, p_{c(k)}^{i+1}=p_{c(k-1)}^{i+1}$.

(3) According to equation (27), the barge acceleration $\ddot{u}_{s(k)}^{i+1}$ at the time of $t_{i+1}$ is calculated.

(4) The barge displacement $u_{s}^{i+1}$ and barge velocity $\dot{u}_{s}^{i+1}$ are calculated by equations (26) and (25).

(5) The impact force of the $k$ th iteration is calculated based on the NSS model in which the equation is expressed as $\bar{p}_{c(k)}^{i+1}=K_{s}\left(u_{s}\right) u_{s}^{i+1}$. The error of two impact forces can be acquired through the equation $\Delta_{s}=\left|\bar{p}_{c(k)}^{i+1}-p_{c(k)}^{i+1}\right|$.

(6) If $\Delta_{s}$ is smaller than the specified value of iteration error, the iteration can be deemed completed. If $\Delta_{s}$ is bigger than the specified value of iteration error, the process should return to step (2) for the iterative convergence of impact force, with $p_{c(k+1)}^{i+1}=\bar{p}_{c(k)}^{i+1}$ and $k=k+1$ set in the new iterative calculation.

The barge impact force to be predicted is the one both obtained from the above iteration and then modified based on the required correction coefficient. 


\section{Validation and Discussion of the SCVIA Model}

5.1. Barge-Rigid Wall Collision. SCVIA only analyzes the conversion between the kinetic energy and the internal energy at barge motion direction. HPFEM analyzes the conversion between the kinetic energy and energies including internal energy, sliding energy, and hourglass energy, and the energy consumption is considered at directions of barge motion and other positions.

In this section, a case of barge-rigid wall collision with barge mass set at $1000 \mathrm{t}$ and impact speed set at $3 \mathrm{~m} / \mathrm{s}$ is studied, the energy and impact force are investigated, which are obtained by SCVIA and HPFEM, and the differences in results between SCVIA and HPFEM are discussed.

Figure 11 shows the energy comparison. Figure 12 illustrates the internal energy calculated by NSS and SCVIA. Figure 13 shows the comparison of different NSS. Figure 14 presents the comparison of impact force. In these figures, NSS-C represents the NSS obtained by the proposed method, and NSS-1 represents the NNS obtained by the HPFEM.

As shown in Figure 11, values of internal energy of the barge obtained by HPFEM are much smaller than the loss of kinetic energy of the barge because $16.6 \%$ kinetic energy is converted into hourglass energy and sliding energy. No matter how NSS is constructed, kinetic energy in SCVIA will be fully converted into internal energy. From this perspective, mechanisms of energy conversion of the HPFEM and SCVIA are not consistent.

As can be seen in Figure 13, the internal energy is the same which is calculated by different NSS with SCVIA, but the internal energy at the same barge deformation is different. This is because although the amount of internal energy of NSS-1 and NSS-C is identical and equal to the barge's initial kinetic energy, the NSS is not the same.

Besides, the bow deformation at the unloading point of NSS-1 obtained from the HPFEM is 1.285 as shown in Figure 12, and the bow deformation at the unloading point calculated from NSS-1 and SCVIA is 0.93 as shown in Figure 13. It indicates that the impact force is not unloaded at deformation as described in the NSS-1 obtained from the HPFEM. This is because the internal energy contained in NSS1 is $4.9 \mathrm{MJ}$, while the initial kinetic energy of the barge is only 4.5 MJ. Therefore, the unloading deformation calculated by NSS- 1 and SCVIA is smaller than that calculated by HPFEM.

As can be seen in Figure 13, the same deformation corresponds to different impact forces calculated between NSS-1 and NSS-C, which leads to different results of impact force time history as shown in Figure 14. The difference of impact force calculated by NSS-1 and NSS-C can be detected after the time of $0.18 \mathrm{~s}$, and the impact force duration calculated by the two NSS is not identical. As revealed from Figure 14, the impact force calculated by the proposed NSS coincides with the one obtained from the HPFEM; it shows the rationality of the proposed NSS in this study.
5.2. Barge-Continuous Rigid-Frame Bridge Collision. In this section, a barge collision simulation is carried out on a threespan continuous rigid frame bridge, with a span layout of $102+168+102 \mathrm{~m}$ and a height of box girder changed by parabola of 1.6 times from the mid-span to the pier top. Pile foundation and high pile cap are used for the bridge substructure. Gravity abutment and the rigid spread foundation are adopted for the abutment. The configuration of the bridge is shown in Figure 15.

A high-precision finite element model of bargebridge collision is established by the use of LS-PREPOST software, which is shown in Figure 16. Pile caps are simulated by solid elements, pier, girder, and pile are simulated by beam elements. The rigid connection is adopted between pile cap and pier, pile cap and pile foundation, as well as pier and girder. As rock is the major feature of the bridge site's geological condition, consolidation is carried out at the junction of the pile foundation and a ground line. The ends of the girder are restrained to prevent the girder's vertical and lateral displacement. The contact between the barge and pier is simulated by surface-to-surface contact.

In the beginning, the proposed method and HPFEM are adopted separately for predicting impact forces. In order to accurately compare the results of the two methods, the two predicted impact forces are applied in the same way on the same bridge finite element model to calculate the dynamic responses of the bridge structure. The impact forces and the dynamic responses respectively generated by the two methods are illustrated in Figures 17-19. Figure 20(a) shows the correlation coefficients of barge impact forces and impact force durations generated by the two methods. Figure 20(b) shows the correlation coefficients of pier top displacement and moment of pier bottom generated by the two methods.

In the three cases of collision, correlation coefficients of impact forces obtained by the proposed method and HPFEM are $0.95,0.86$, and 0.97 , respectively. The correlation coefficients of pier bottom moment are $0.99,0.94$, and 0.98 , respectively. The results indicate a good correlation of the barge impact forces and moment of pier bottom predicted by the two methods. The above analysis shows the good precision of the proposed method.

Correlation coefficients of pier top displacement in the three cases are 0.99, 0.68, and 0.99, respectively. Except for the case of a $1000 \mathrm{t}$ barge impact bridge with a velocity of $4 \mathrm{~m} / \mathrm{s}$ is less satisfactory, other results calculated by the proposed method are well consistent with those of the HPFEM. It should be noted that although the maximum displacement of the pier top calculated by the proposed method is larger than the one obtained in the HPFEM in the case of $1000 \mathrm{t}-4 \mathrm{~m} / \mathrm{s}$, it is still feasible in engineering applications. Generally, less time is consumed, and higher efficiency is ensured for the calculation of the proposed method than the HPFEM. 


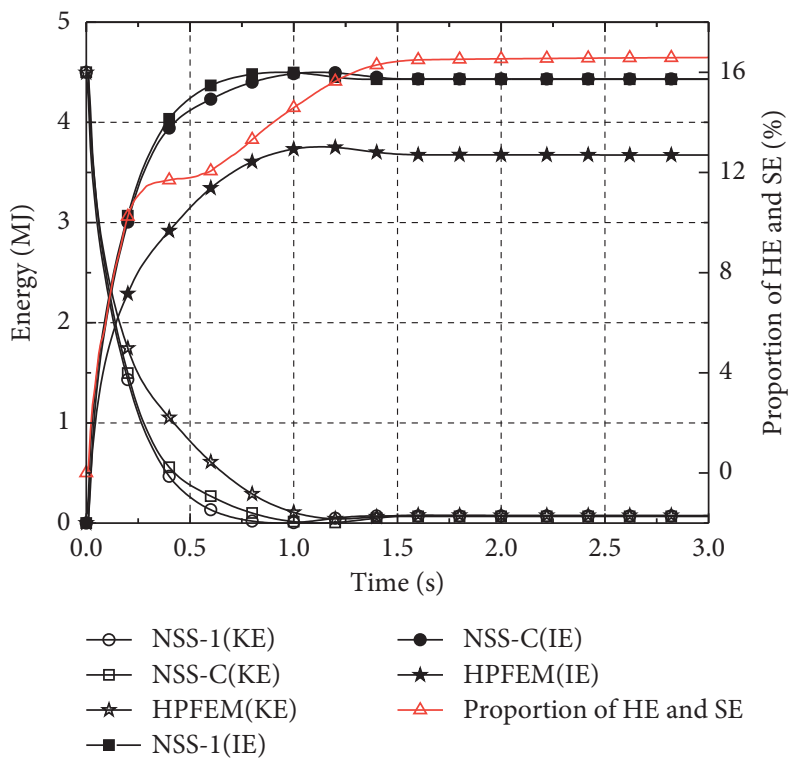

Figure 11: Energy comparison.

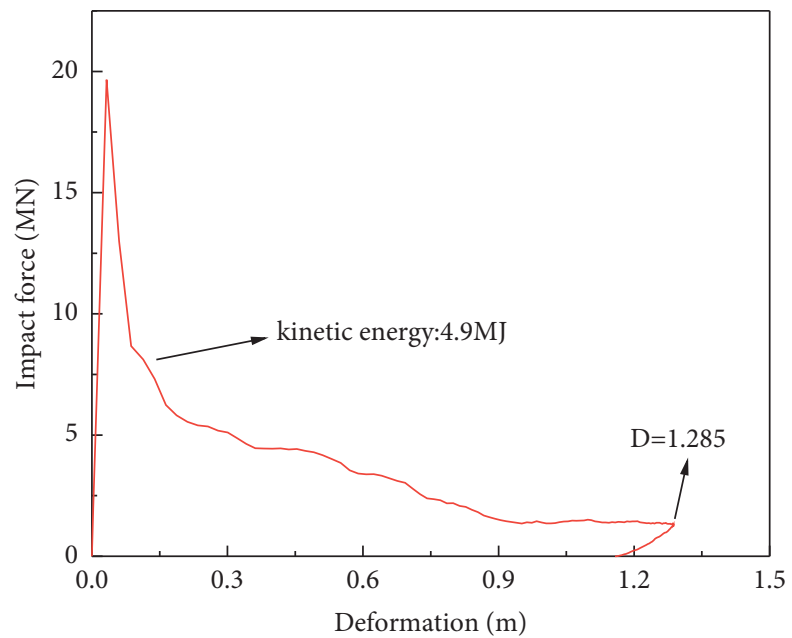

Figure 12: $a-P(a)$ calculated by HPFEM.

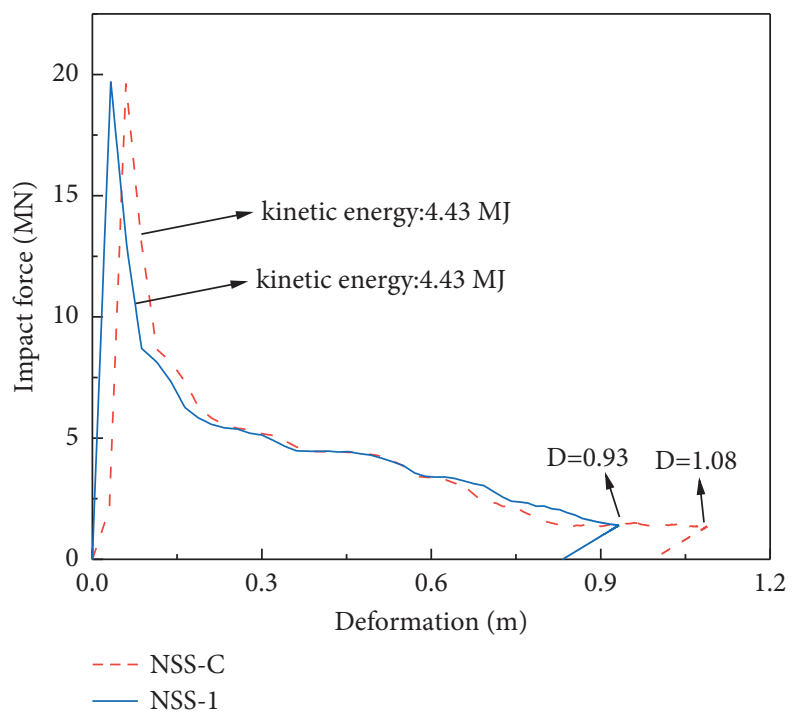

Figure 13: $a-P(a)$ comparison calculated by NSS and SCVIA. 


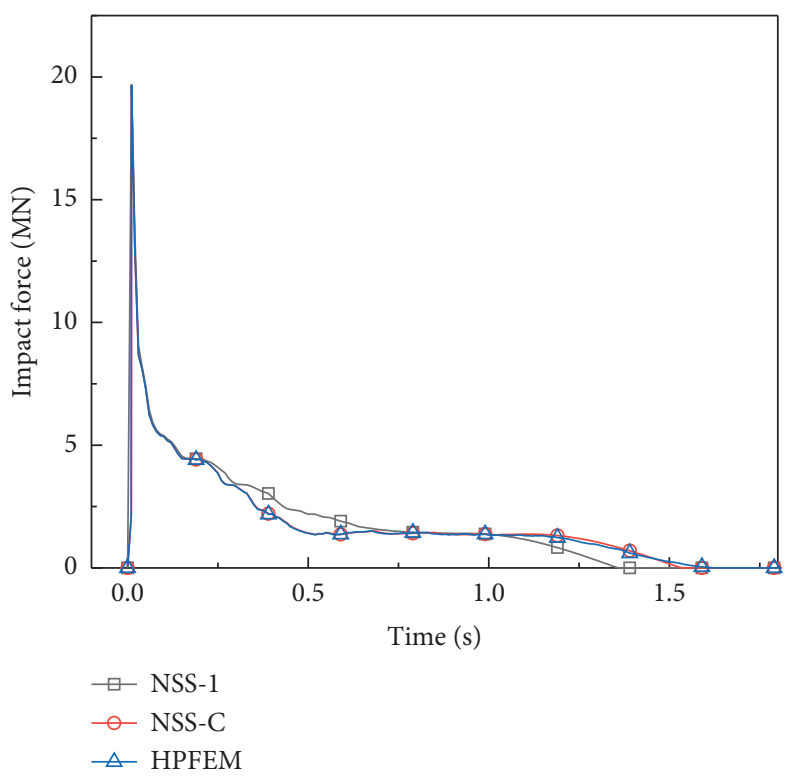

FIgURE 14: Impact force comparison.

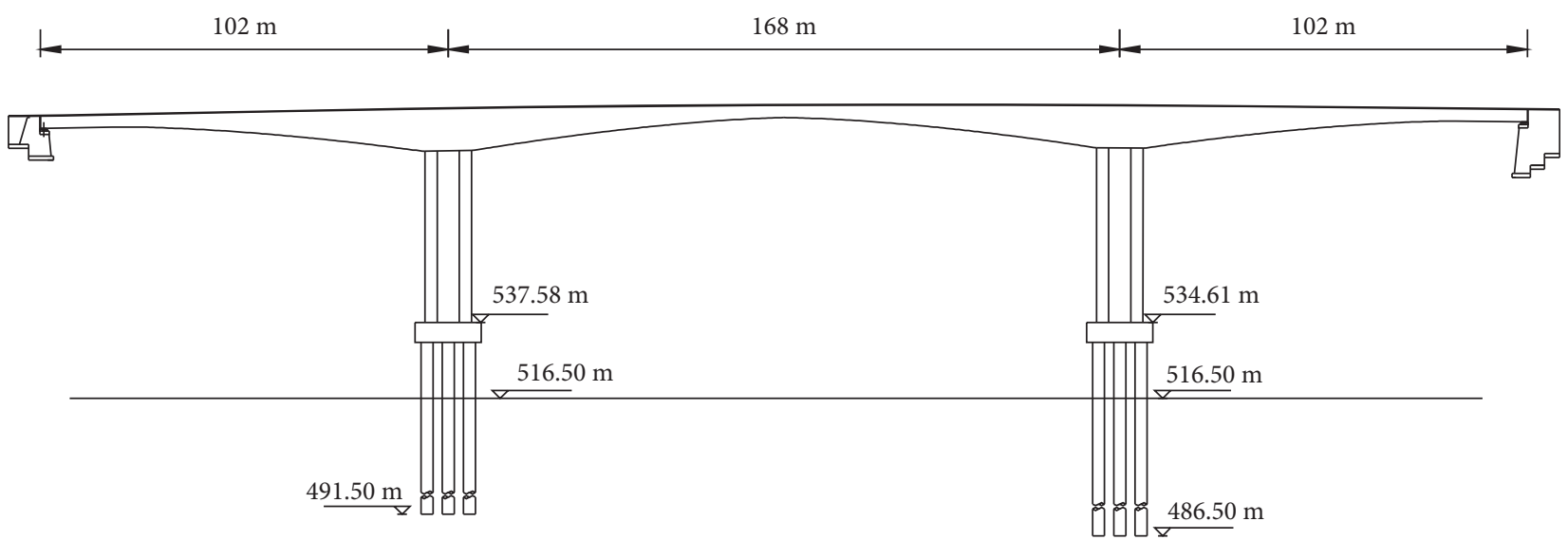

(a)
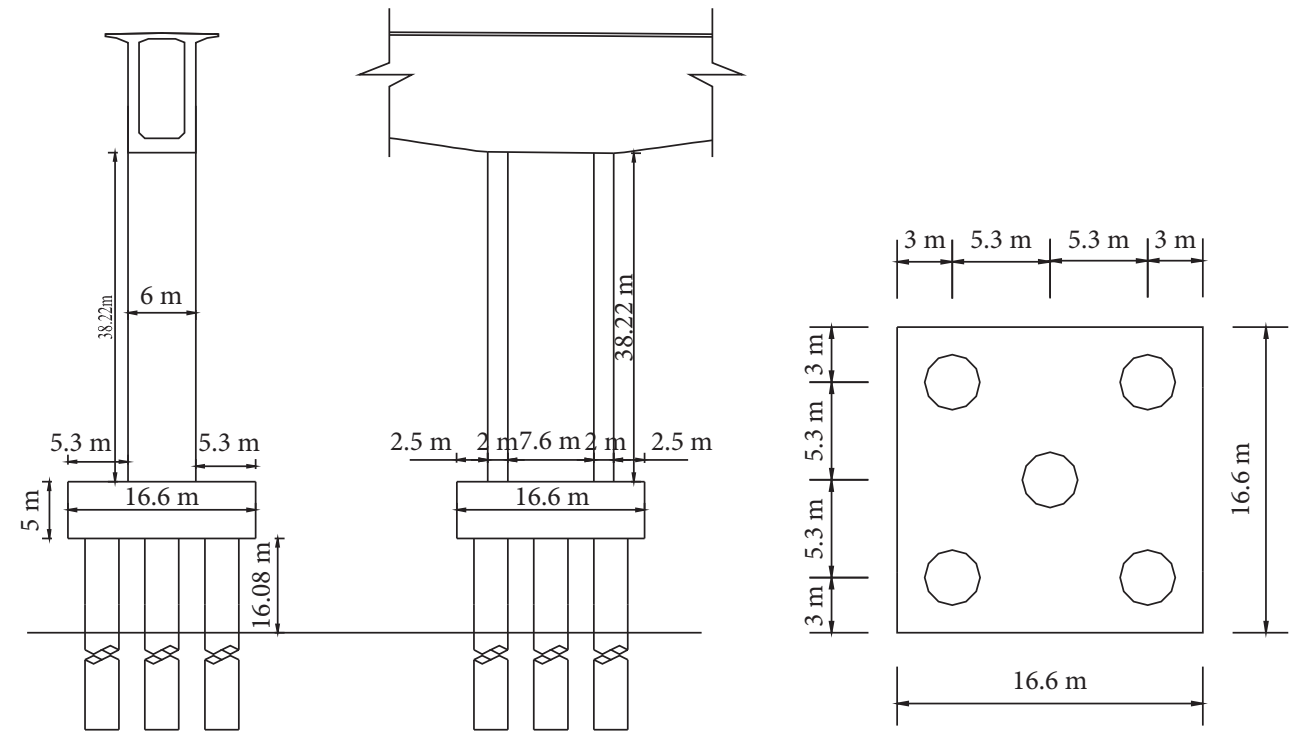

(b)

FIgURE 15: Configuration of the bridge. (a) Elevation view. (b) Left: side view of the pier; bottom middle: front view of the pier; and right: plan view of the pier. 


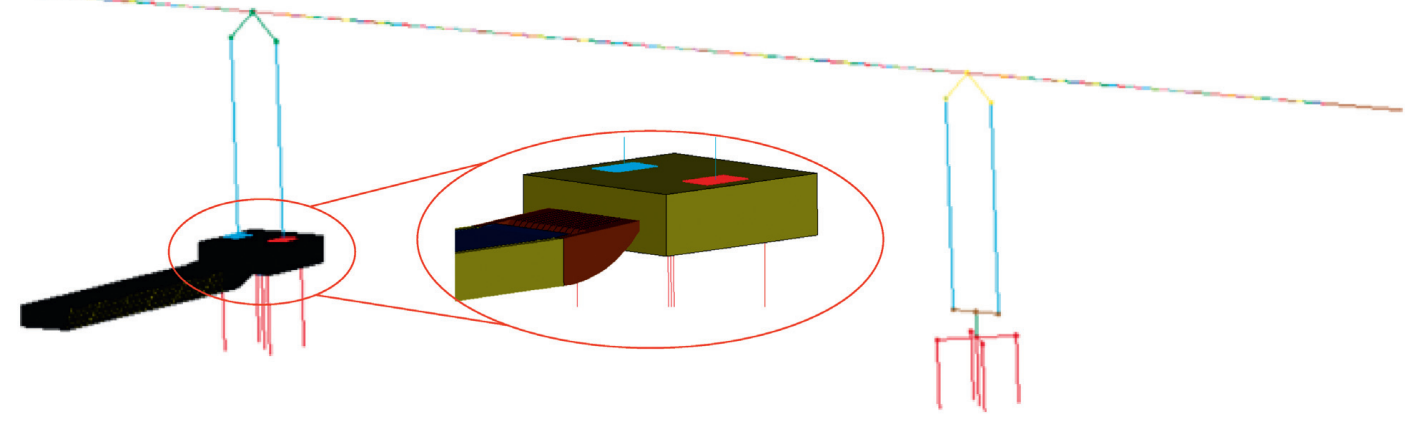

FIGURE 16: Finite element method model of barge-continuous rigid-frame bridge collision.

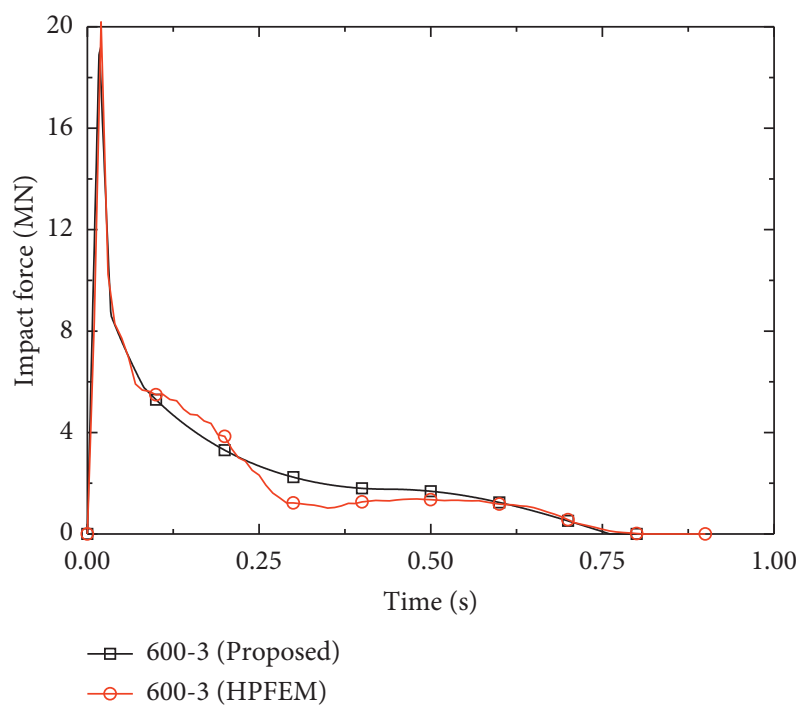

(a)

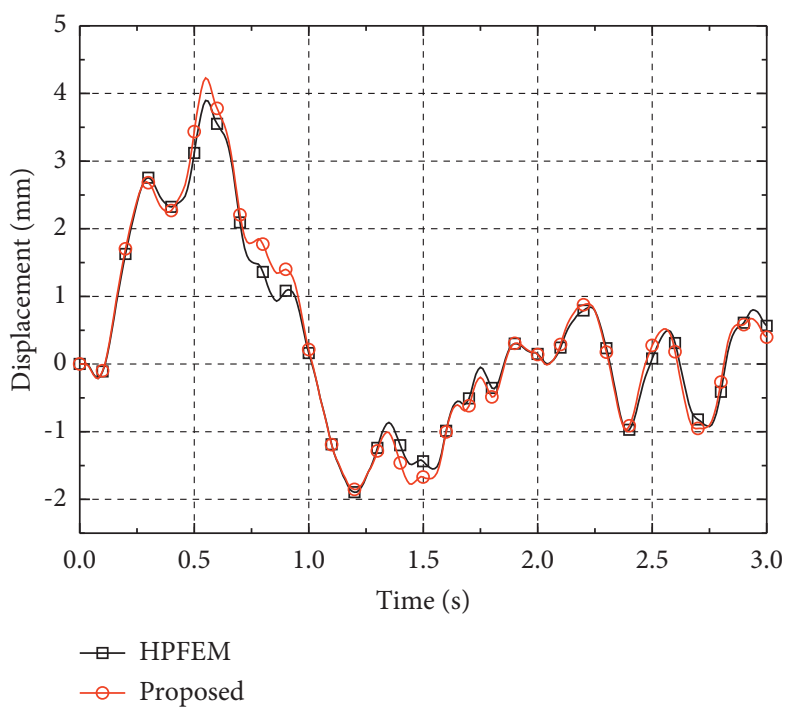

(b)

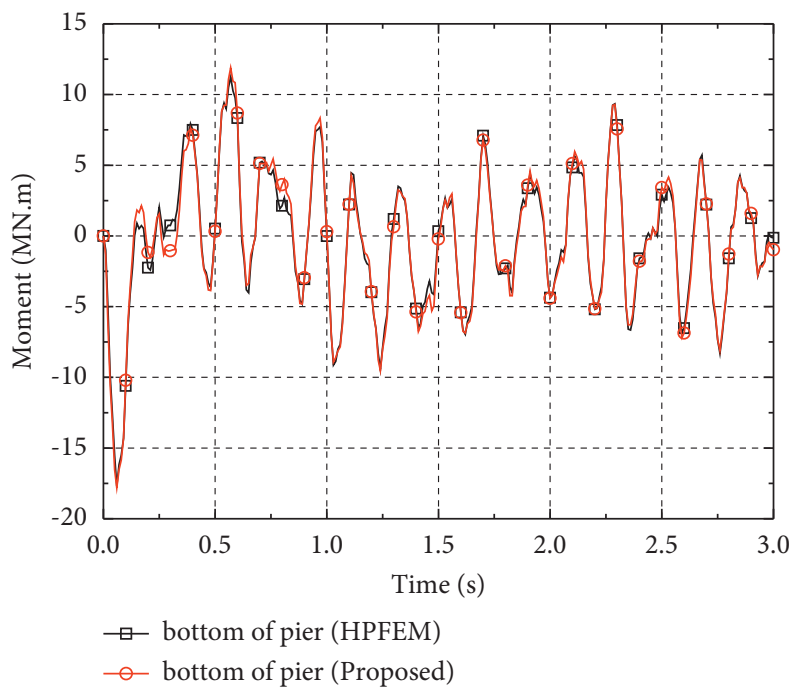

(c)

FIGURE 17: Results of a simulation of a collision by a 600 -ton barge at the impact velocity of $3 \mathrm{~m} / \mathrm{s}$. (a) Time history of impact force $(600 \mathrm{t}+3 \mathrm{~m} / \mathrm{s})$. (b) Time history of displacement of pier top $(600 \mathrm{t}+3 \mathrm{~m} / \mathrm{s})$. (c) Time history of moment of pier bottom $(600 \mathrm{t}+3 \mathrm{~m} / \mathrm{s})$. 


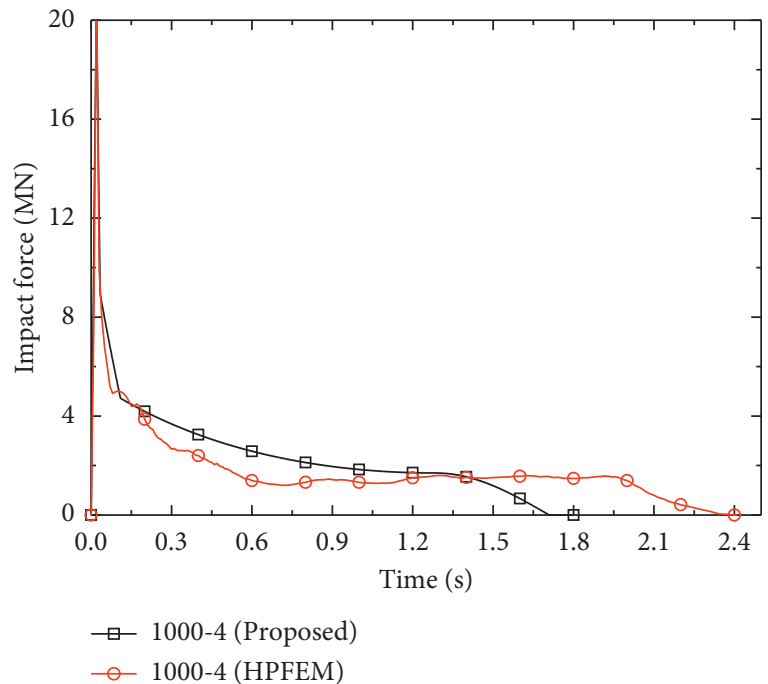

(a)

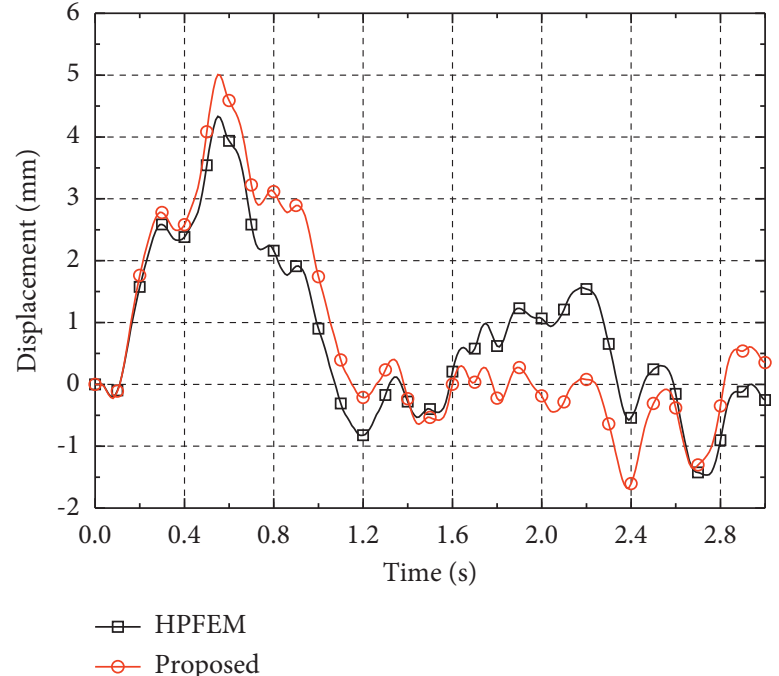

(b)

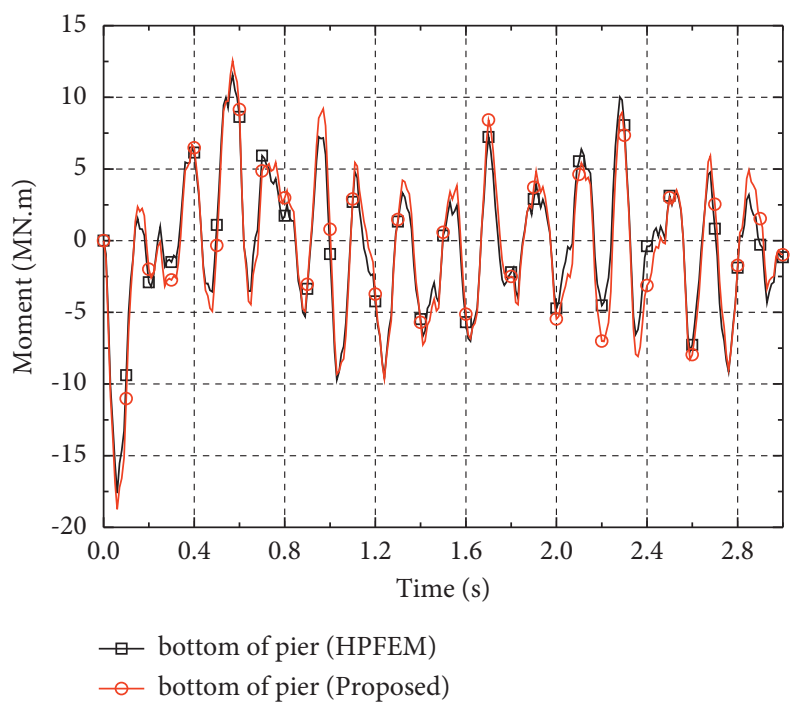

(c)

Figure 18: Results of a simulation of a collision by a 1000-ton barge at the impact velocity of $4 \mathrm{~m} / \mathrm{s}$. (a) Time history of impact force $(1000 \mathrm{t}+4 \mathrm{~m} / \mathrm{s})$. (b) Time history of displacement of pier top $(1000 \mathrm{t}+4 \mathrm{~m} / \mathrm{s})$. (c) Time history of moment of pier bottom (1000 $\mathrm{t}+4 \mathrm{~m} / \mathrm{s})$. 


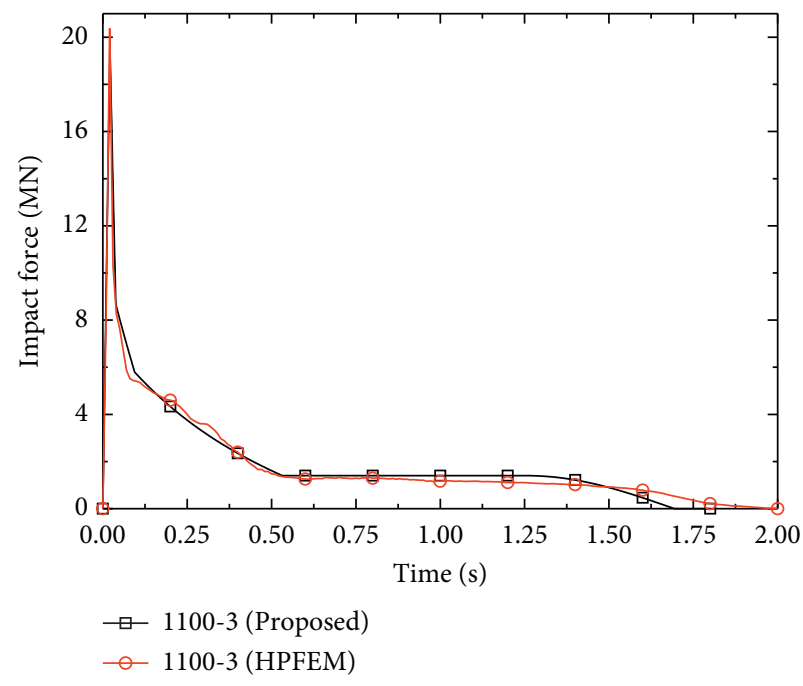

(a)

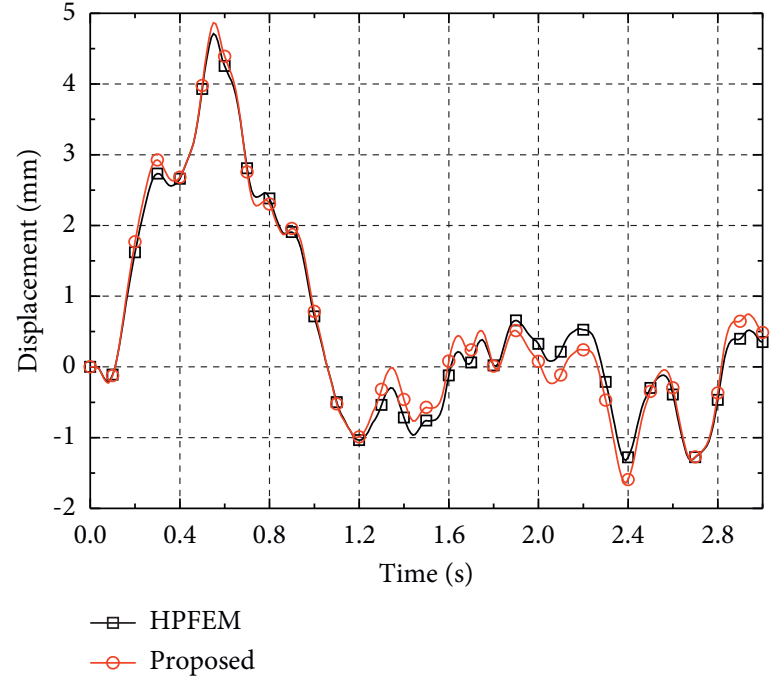

(b)

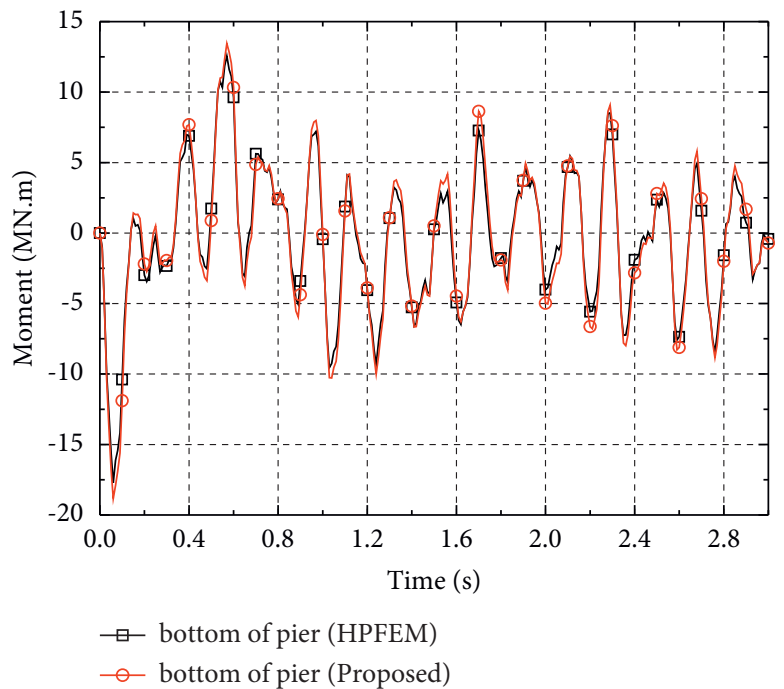

(c)

FIGURE 19: Results of a simulation of a collision by a 1100 -ton barge at the impact velocity of $3 \mathrm{~m} / \mathrm{s}$. (a) Time history of impact force $(1100 t+3 \mathrm{~m} / \mathrm{s})$. (b) Time history of displacement of pier top $(1100 \mathrm{t}+3 \mathrm{~m} / \mathrm{s})$. (c) Time history of moment of pier bottom $(1100 \mathrm{t}+3 \mathrm{~m} / \mathrm{s})$.

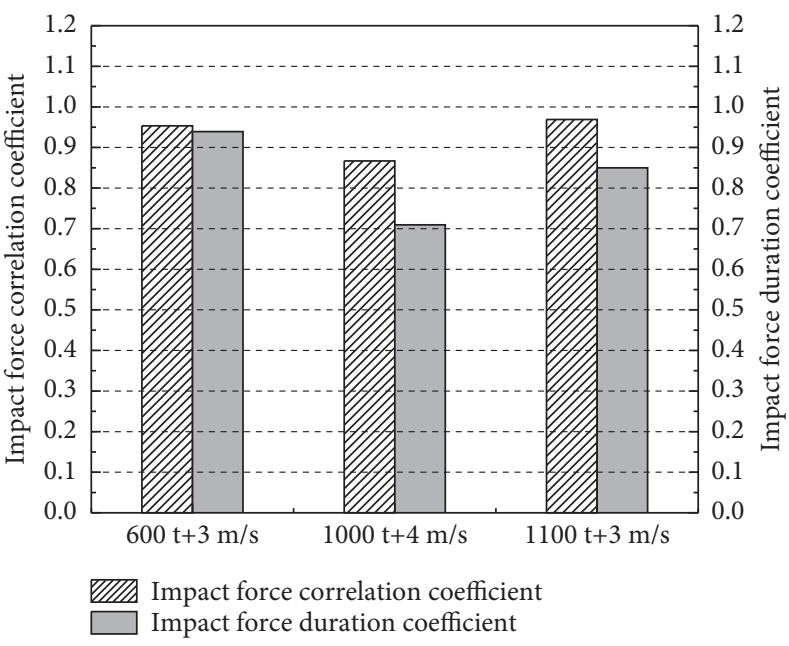

(a)

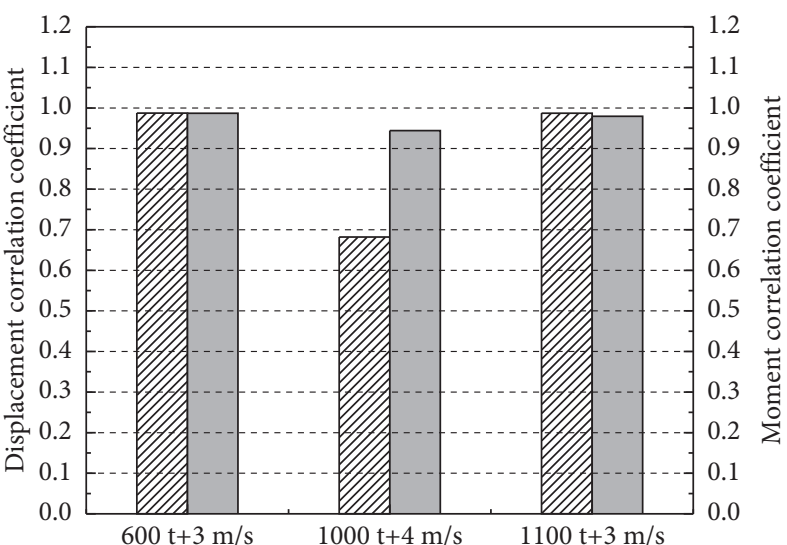

Displacement correlation coefficient Moment correlation coefficient

(b)

FIgURe 20: Correlation coefficient of simulation results. (a) Impact force c.c. R2 and impact force duration coefficient ET. (b) Correlation coefficients of displacement of pier top and moment of pier bottom. 


\section{Conclusions}

This study focuses on investigating the construction method of NSS and the prediction method of impact force for bargebridge collision. Based on the comparisons between characteristics of analyses on energy conservation and momentum variation between HPFEM and CVIA, the new construction method of NSS and the prediction method of impact force are proposed. Conclusions are as follows:

(1) The HPFEM involves the conversion of kinetic energy, internal energy, hourglass energy, and sliding energy, while the CVIA only involves the conversion between internal energy and kinetic energy. When the NSS is obtained directly from the relationship between bow deformation and impact forces calculated by HPFEM, the internal energy calculated by the NSS curve is different from that of the HPFEM.

(2) When the $a-P(a)$ curve directly obtained from HPFEM is used in CVIA calculation, and the impact force is inconsistent with that calculated by HPFEM, the NSS should be modified. A construction method of NSS is proposed, whose essence is adjustment about bow deformation of NSS obtained by HPFEM. The calculated results showed that the proposed method can be identified with those from the HPFEM.

(3) According to the proposed method, the NSS is established based on barge-rigid wall collision under the condition of different barge mass and impact velocity. The NSS can be simplified as a polyline model with five line segments, and the four points of the polyline are determined by the RSM equation. Then, the initial kinetic energy, barge mass, and impact velocity substitute into the RSM equation, and the NSS can be obtained.

(4) Based on the proposed NSS model, the SCVIA is proposed. The feasibility of the proposed NSS and impact force prediction method is validated by case studies on barge-rigid wall collision and bargebridge collision.

\section{Data Availability}

All data, models, and codes generated or used during the study are included within this article.

\section{Conflicts of Interest}

The authors declare that they have no conflicts of interest regarding the publication of this paper.

\section{Acknowledgments}

This research was supported by Sichuan Science and Technology Program (Grant no. 2017JY0514), the National Key Research and Development Program of China (Grant no. 2016YFB1200401), and the National Natural Science Foundation of China (Grant no. 51878564).

\section{References}

[1] G. Woisin, "The collision tests of the GKSS," Jahrbuch der Schiffbautechnischen Gesellschaft, vol. 70, pp. 465-487, 1976.

[2] AASHTO, Guide Specification and Commentary for Vessel Collision Design of Highway Bridges, AASHTO Standards, Washington, D.C USA., 2009.

[3] Y. Sha and H. Hao, "Nonlinear finite element analysis of barge collision with a single bridge pier," Engineering Structures, vol. 41, pp. 63-76, 2012.

[4] Y. Sha and H. Hao, "Laboratory tests and numerical simulations of barge impact on circular reinforced concrete piers," Engineering Structures, vol. 46, pp. 593-605, 2013.

[5] J. Travanca and H. Hao, "Numerical analysis of steel tubular member response to ship bow impacts," International Journal of Impact Engineering, vol. 64, pp. 101-121, 2014.

[6] G. C. Kantrales, G. R. Consolazio, D. Wagner, and S. Fallaha, "Experimental and analytical study of high-level barge deformation for barge-bridge collision design," Journal of Bridge Engineering, vol. 21, no. 2, Article ID 04015039, 2016.

[7] J. J. Wang, Y. C. Song, W. Wang, and J. Li, "Calibrations of numerical models by experimental impact tests using scaled steel boxes," Engineering Structures, vol. 173, pp. 481-494, 2018.

[8] Q. Pu, J. Liu, H. Gou, Y. Bao, and H. Xie, "Finite element analysis of long-span rail-cum-road cable-stayed bridge subjected to ship collision," Advances in Structural Engineering, vol. 22, no. 11, pp. 2530-2542, 2019.

[9] W. Fan, D. Shen, X. Huang, and Y. Sun, "Reinforced concrete bridge structures under barge impacts: FE modeling, dynamic behaviors, and UHPFRC-based strengthening," Ocean Engineering, vol. 216, Article ID 108116, 2020.

[10] G. R. Consolazio and D. R. Cowan, "Numerically efficient dynamic analysis of barge collisions with bridge piers," Journal of Structural Engineering, vol. 131, no. 8, pp. 12561266, 2005.

[11] D. R. Cowan, Development of time-history and response spectrum analysis procedures for determining bridge response to barge impact, $\mathrm{PhD}$ Thesis, University of Florida, Gainesville, FL, USA, 2007.

[12] J. Zhang, X. Chen, D. Liu, and X. Li, "Analysis of bridge response to barge collision: refined impact force models and some new insights," Advances in Structural Engineering, vol. 19, no. 8, pp. 1224-1244, 2016.

[13] W. Fan, Y. Liu, B. Liu, and W. Guo, "Dynamic ship-impact load on bridge structures emphasizing shock spectrum approximation," Journal of Bridge Engineering, vol. 21, no. 10, Article ID 04016057, 2016.

[14] J. L. Hendrix, "Dynamic analysis techniques for quantifying bridge pier response to barge impacting loads," Master's Thesis, University of Florida, Gainesville, FL, USA, 2003.

[15] B. B. Zhang, "Influence of pier nonlinear, impact angle and column shape on pier response to barge impact loading," Master's Thesis, University of Florida, Gainesville, FL, USA, 2004.

[16] P. Yuan and I. E. Harik, "One-dimensional model for multibarge flotillas impacting bridge piers," Computer-Aided Civil and Infrastructure Engineering, vol. 23, no. 6, pp. 437-447, 2008.

[17] K. E. Meir-Dornberg, "Ship collisions, safety zones, and loading assumptions for structures in inland waterways," VDI-berichte, vol. 496, pp. 1-9, 1983.

[18] W. Fan, W. Yuan, Z. Yang, and Q. Fan, "Dynamic demand of bridge structure subjected to vessel impact using simplified 
interaction model," Journal of Bridge Engineering, vol. 16, no. 1, pp. 117-126, 2011.

[19] W. Fan and W. C. Yuan, "Ship bow force-deformation curves for ship-impact demand of bridges considering effect of pilecap depth," Shock and Vibration, vol. 2014, pp. 1-19, Article ID 201425, 2014.

[20] J. J. Wang, Y. C. Song, and L. T. Bu, "Probabbilistic model of impact force-penetration for ship-bridge collision," China Journal of Highway and Transport, vol. 27, no. 6, pp. 59-67, 2014, in Chinese.

[21] G. R. Consolazio, M. T. Davidson, and D. R. Cowan, "Barge bow force-deformation relationships for barge-bridge collision analysis," Transportation Research Record: Journal of the Transportation Research Board, vol. 2131, no. 1, pp. 3-14, 2009.

[22] G. R. Consolazio and D. R. Cowan, "Nonlinear analysis of barge crush behavior and its relationship to impact resistant bridge design," Computers \& Structures, vol. 81, no. 8-11, pp. 547-557, 2003.

[23] P. Yuan and I. E. Harik, "Equivalent barge and flotilla impact forces on bridge piers," Journal of Bridge Engineering, vol. 15, no. 5, pp. 523-532, 2010.

[24] W. Fan, W. C. Yuan, Z. Yang, and Q. W. Fan, “Development of time history analysis for dynamic demand of elevated pile cap bridge subjected to vessel collision," Journal of Tongji University, vol. 38, no. 12, pp. 1719-1724, 2010, in Chinese.

[25] C. G. Bucher and U. Bourgund, "A fast and efficient response surface approach for structural reliability problems," Structural Safety, vol. 7, no. 1, pp. 57-66, 1990.

[26] R. W. Clough and J. Penzien, Dynamics of Structures, McGraw-Hill, New York, NY, USA, 1993. 